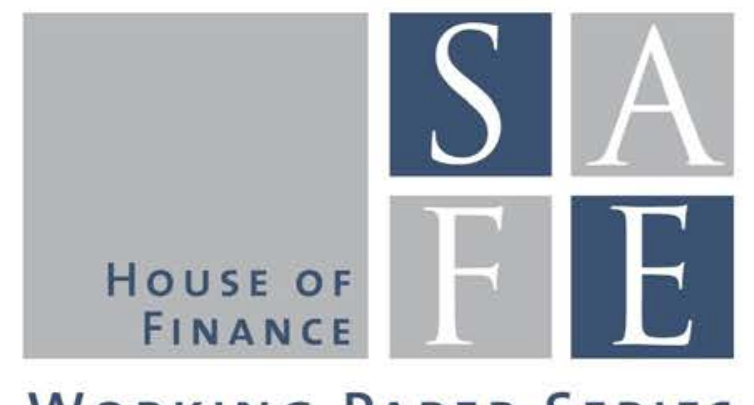

Working PAPER SERIES

Joost Driessen - Theo E. Nijman - Zorka Simon

\title{
Much Ado About Nothing: A Study of Differential Pricing and Liquidity of Short and Long Term Bonds
}

SAFE Working Paper No. 238

SAFE I Sustainable Architecture for Finance in Europe A cooperation of the Center for Financial Studies and Goethe University Frankfurt 


\section{Non-Technical Summary}

European pension funds and insurers managed more than $€ 7$ trillion worth of assets in 2016. For these institutions, it is crucially important to attain precise estimates of long term discount rates for their asset management and valuation of liabilities for regulatory purposes. Despite its practical importance and potential welfare consequences, modelling and examining the long end of the nominal term structure has attracted little attention in the academic literature. This paper aims to fill this gap by studying the differential pricing of short and long maturity bonds, especially focusing on segmentation in yields and liquidity.

We explore the channels through which market segmentation affects the pricing of the short and long ends of the German nominal term structure between 2005 and 2015. We find that although there are statistically significant differences in the pricing and yield drivers of short and long maturity bonds, the corresponding economic effects are rather small. To deepen our understanding of time-series drivers of short and long maturity bond yields, we study their exposures to proxies of demand pressure, default premiums and liquidity. Our yield decomposition reveals little evidence of significant segmentation in the German sovereign bond market: this means that yields of long term bonds are not extensively distorted by demand pressure, default or liquidity premiums, therefore there is little indication for substantial yield segmentation. Next, we present evidence for some degree of liquidity segmentation across short and long maturities. We show that the nature of liquidity varies along the curve: liquidity of short maturity bonds seems more systematic in nature, whilst liquidity of long maturity bonds behaves independently from other market measures. These results seem plausible as long maturity bonds are likely to be held by long horizon buy-and-hold investors, who might be inherently less concerned about the issue level illiquidity and cost of trading. As opposed to this, investors of shorter maturity bonds are likely to rebalance their portfolios more frequently, or liquidate some of their assets under tightening market and funding conditions.

Finding that long maturity bond yields are not substantially distorted has important policy implications. Part of the policy discussion on valuation of pension and insurance liabilities for regulatory purposes is how to model long term discount rates. The current approach is based on the ultimate forward rate method, which is an extrapolation technique used to calculate discount rates for maturities beyond the assumed last liquid point of the yield curve, often relying on the use of interest rate swaps. However, in light of our results, parts of this practice seem unnecessary: if long maturity bond yields are not distorted, we could extrapolate long term discount rates from these yields observed in bond markets. Then the question arises: is the ultimate forward rate discussion much ado about nothing? One the one hand, definitely not, as pension funds and insurers manage a vast amount of wealth, and thus making sure that this wealth is properly valuated is crucial. On the other hand, the answer is probably yes: it seems that we can trust yields of long maturity bonds, as any existing effects of segmentation on yields or liquidity are rather small, and therefore use them for regulatory valuation. 


\title{
Much ado about nothing: A study of differential pricing and liquidity of short and long term bonds
}

\author{
Joost Driessen $^{1}$, Theo E. Nijman ${ }^{1}$, and Zorka Simon*2 \\ ${ }^{1}$ Tilburg University and Netspar \\ ${ }^{2}$ Research Center SAFE - Goethe University Frankfurt
}

November 2018

\begin{abstract}
Are yields of long-maturity bonds distorted by demand pressure of clientele investors, regulatory effects, or default, flight-to-safety or liquidity premiums? Using data on German nominal bonds between 2005 and 2015, we study the differential pricing and liquidity of short and long maturity bonds. We find statistically significant, but economically negligible segmentation in yields and some degree of liquidity segmentation of short-term versus long-term bonds. These results have important policy implications for the $€ 17.5$ trillion European pension and insurance industries: long maturity bond yields seem appropriate for the valuation of long-term liabilities.
\end{abstract}

Keywords: Sovereign Bonds, Term Structure of Interest Rates, Segmentation, Liquidity, Flight-to-safety, Credit Risk, Unconventional Monetary Policy.

JEL classification: G01, G12, G15, G18.

*Email address of authors: j.j.a.g.driessen@uvt.nl, nyman@tilburguniversity.edu, and simon@safe.uni-frankfurt.de

We would like to thank Anne G. Balter (discussant), Dion Bongaerts, Paolo Colla (discussant), Frank de Jong, Daniel Havran (discussant), Stefan Ruenzi and the conference and seminar participants of the Summer Workshop of the Hungarian Academy of Sciences, the 7th Annual Financial Market Liquidity Conference, the 2017 Netspar Internationa Pension Workshop, the Finanzagentur GmbH, the 2017 FMA Boston, and the Securities Markets: Trends, Risks, Policies conference by Consob-Bocconi. Zorka Simon gratefully acknowledges research support from the Research Center SAFE, funded by the State of Hessen initiative for research LOEWE. 


\title{
Much ado about nothing: A study of differential pricing and liquidity of short and long term bonds
}

\author{
November 2018
}

\begin{abstract}
Are yields of long-maturity bonds distorted by demand pressure of clientele investors, regulatory effects, or default, flight-to-safety or liquidity premiums? Using data on German nominal bonds between 2005 and 2015, we study the differential pricing and liquidity of short and long maturity bonds. We find statistically significant, but economically negligible segmentation in yields and some degree of liquidity segmentation of short-term versus long-term bonds. These results have important policy implications for the $€ 17.5$ trillion European pension and insurance industries: long maturity bond yields seem appropriate for the valuation of long-term liabilities.
\end{abstract}

Keywords: Sovereign Bonds, Term Structure of Interest Rates, Segmentation, Liquidity, Flight-to-safety, Credit Risk, Unconventional Monetary Policy.

JEL classification: G01, G12, G15, G18. 


\section{Introduction}

European pension funds and insurers managed more than $€ 7.5$ and $€ 10.1$ trillion worth of assets in 2016, respectively (Investment and Pensions Europe, 2017; Insurance Europe, 2018). For these institutions it is crucially important to attain precise estimates of long-term discount rates for their asset management and valuation of liabilities for regulatory purposes. Despite its practical importance and potential welfare consequences, modelling and examining the long end of the nominal term structure has attracted little attention in the academic literature ${ }^{1}$.

This paper aims to fill this gap by studying the differential pricing of short and long maturity bonds, especially focusing on the effect of segmentation on yields and liquidity. To address this question, we explore the channels through which this affects the pricing of the short and long ends of the German nominal term structure between 2005 and 2015. In this period, it is conceivable that there was investor segmentation or formation of clienteles due to regulation-induced demand pressure or the effect of unconventional monetary policy on yields. Liquidity differences have arisen during the financial crisis, while during the euro crisis potential credit premium differences could have emerged, alongside with the effect of safe haven flows of Eurozone investors. The confounding presence of these forces makes this market and time period an ideal testing ground to study whether these events have a differential effect on long and short maturity bonds.

The key result of our paper is that although there are statistically significant differences in the pricing and drivers of short and long maturity bonds, the corresponding economic effects are rather small. This means that as opposed to expectations, observed long yields are not extensively distorted by demand pressure, default or liquidity premiums, therefore there is little evidence for substantial yield segmentation. This finding has important policy implications. Part of the policy discussion on the valuation of pension and insurance liabilities is how to model long term discount rates. The current Eurozone-wide

\footnotetext{
${ }^{1}$ With the notable exceptions of Greenwood and Vissing-Jorgensen (2018) and Christensen et al. (2018).
} 
approach is based on the ultimate forward rate method, which is an extrapolation technique used to calculate discount rates for maturities beyond the so-called "last liquid point" (LLP). For longer maturities, there is a variety of methods that use interest rate swaps. However, in light of our results, this practice seems unnecessary: if long maturity bond yields are not distorted, we could extrapolate long term discount rates from these yields observed in the bond market. Is the ultimate forward rate discussion much ado about nothing? One the one hand, there is a lot of money at stake, thus making sure that this wealth is properly valuated is crucial. On the other hand, it seems that we can trust yields of long maturity bonds, as any existing effects of yield segmentation are negligibly small.

Our second key finding is that we present evidence of the differential effect of segmentation on liquidity across short and long maturities. This finding is in line with Amihud and Mendelson (1986); Beber et al. (2012), as we show that the nature of liquidity varies along the yield curve: liquidity of short maturity bonds is more systematic in nature, whilst liquidity of long maturity bonds behaves independently from other market measures. These results are plausible, as long maturity bonds are likely held by long horizon, buy-and-hold investors, who most of the times are inherently less concerned about the issue level illiquidity and cost of trading, as opposed to investors of shorter maturity bonds, who trade more due to shorter invesment mandates and frequent rebalancing schedules.

Our empirical approach is as follows. First, to study segmentation, we construct a pair of measures similar to that of $\mathrm{Hu}$ et al. (2013). The noise measure is a liquidity proxy that is based on the pricing errors of observable yields compared to a smooth theoretical yield curve. We fit a Nelson-Siegel model to bonds up to twenty years of maturity to determine the theoretical curve, which we extrapolate for longer maturities.Next, we construct two measures of noise that allow us to focus on deviations of long and shorter maturities separately: the average root mean squared pricing error for maturities less than 20 years is 7.91 basis points, while it is 19.39 basis points for maturities longer than the UFR 
inspired 20-year LLP. The size of the long noise measure suggests that with even such a simple model we get good predictions of long maturity bond yields./footnoteIn taking the 20-year cut-off, we follow the European UFR discussion, therefore testing whether this cut-off should be set at any other point of the yield curve is beyond the scope of this paper. We find that the two measures proxy for different aspects of liquidity: short noise is related to the age of the bond and to market and funding liquidity; while long noise is linked to bond issue level illiquidity and the US noise measure. Nevertheless, the low explanatory power of conventional liquidity proxies suggests that the two noise measures capture an aspect of illiquidity that correlates, but goes beyond traditional liquidity measures, as in $\mathrm{Hu}$ et al. (2013).

Next, to further examine the pricing of bonds, we also look at the average fitting error of long maturity bonds, called the bias. This fitting error is on average -9.25 basis points, and is persistently negative, that is the observed long yields are consistently below those implied by our pricing model ${ }^{2}$. In search for the reason why long yields are "too low", we find that the bias is linked to the Roll implied bid-ask spread, time to maturity of bonds, liquidity risk, the Ted spread, flight-to-safety flows and the credit risk of Germany. To deepen our understanding of the time-series drivers of short and long-term bond yields, we study their exposures to proxies of demand pressure, default premium and liquidity. Our yield decomposition reveals little evidence of significant segmentation in German sovereign bond markets. Short yields are driven by short noise and large scale asset purchases; the latter is indirect evidence that these unconventional monetary measures have an effect on yields of targeted maturities. Additionally, we find that both long and short yields are strongly linked to German credit quality and flight-to-safety flows. This suggests that when periphery credit quality declines, the overall German yield curve becomes a target to safe haven flows. Although these results are statistically significant, the economic effects, measured by the standard deviation change of the explanatory variables, are in the magnitude of 1-3 basis points.

\footnotetext{
${ }^{2}$ However, the difference between the observed and fitted yields is economically small, especially given the simple yield curve model in our analysis.
} 
Looking at the effect segmentation on liquidity, we study how yields of the short and long ends of the yield curve are linked to a wide range of liquidity measures. The effect of short noise on the average short yield is significant and robust to the inclusion of other measures, and it varies over time. In the contrary, we find that the average long yield has a weaker connection to long noise, while we find evidence of liquidity spillover from the short to the long end of the yield curve. We also consider if short and long noise are related to different market forces, and find that short noise is sensitive to large scale asset purchases of the ECB, as well as to changes in stock market volatility and flight-to-safety flows. The long noise measure has a similar relationship to safe haven flows, however, it is also sensitive to declining credit quality of the issuer, as well as to breakup risk.

\section{Literature overview}

This paper studies the differential pricing of short and long maturity bonds, especially focusing on segmentation in yields and liquidity. But why would there be differences that are maturity dependent? In answering this question, we build on previous research on market segmentation, limits of arbitrage, liquidity and credit risk of sovereign bonds, the term structure of liquidity premium, flights-to-safety and the effects of unconventional monetary policy on sovereign bond yields. Nonetheless, the distinctive feature of our analysis is that we take a comprehensive approach of examining yields and liquidity features of bonds from a wide range of the maturity spectrum. In particular, we focus on bonds with tenors between 2 to 30 years to study the differential effect and channels of demand pressure, default risk and liquidity along the yield curve. To do so, we use a method closely related to $\mathrm{Hu}$ et al. (2013).

Hu et al. (2013), henceforth HPW, develop a measure of bond liquidity that is based on the pricing error of observable yields compared to a theoretical smooth curve. They show that this measure is linked to the amount of arbitrage capital on the market: the pricing error is larger and more persistent when funding liquidity conditions deteriorate and 
arbitrageurs lack the resources to trade substantial price deviations away. We construct a similar measure, but instead of aggregating all information along the yield curve, we focus on deviations of long and shorter maturities separately. These two measures of noise help us explore how prices and liquidity can differ across maturities. First, some investors might not have access to the overall yield curve due to either regulatory constraints or endogenous choice regarding their investment horizon. This gives rise to market segmentation. Second, if local demand shocks are accompanied by limited arbitrage capital, pricing inefficiencies cannot be eliminated and become persistent. Third, if short and long maturity bonds are exposed to risk factors to a different extent, different levels of risk premiums will emerge.

Addressing the first explanation, we contribute to the literature on market segmentation. Among other factors, such as time-varying expectations of future rates, changes in bonds yields can be attributed to shifts in demand or supply. On the one hand, bond demand might be driven by preferred habitat investors. Vayanos and Vila (2009) show that if investors have preferences for specific maturities, bond markets become segmented, in which case demand shocks affect the cross-section of bonds differently. Greenwood and Vayanos (2010) provide empirical evidence for a preferred habitat induced demand shock following the 2004 UK pension reform. Related to this, our study also aims to deepen the understanding of how demand pressure due to regulatory changes, specifically those concerning the natural clientele of the bonds in our sample, affect yields and liquidity in the cross-section of maturities. On the other hand, supply factors also play a role in the determination of yields. Greenwood and Vayanos (2014) and Guibaud et al. (2013) present models of how supply and maturity structure of sovereign debt influences bond yields.

Another channel through which local demand pressure arises is unconventional monetary policy. ${ }^{3}$ While Krishnamurthy and Vissing-Jorgensen (2011) show that quantitative easing (QE) in the US caused a supply shortage for certain clientele demand, pushing

\footnotetext{
${ }^{3}$ A study that focuses on buyback programs of specicif maturities is that of Phillips (2003), who documents significant bond market reactions to Treasury announcements of 30-year bond buybacks.
} 
yields downwards, Christensen and Gillan (2013) provide evidence on how market liquidity is improved by such measures. D'Amico et al. (2012) present similar evidence on the effect of large-scale asset purchase programs (LSAP) on the preferred habitat and duration of sovereign bonds, alongside with D'Amico and King (2013) who show that LSAP often causes market segmentation. There is also growing evidence from the intervention of the European Central Bank (Eser and Schwaab, 2016; Krishnamurthy et al., 2018) and its effect on the liquidity of European sovereign bond markets (De Pooter et al., 2013; Pelizzon et al., 2014, 2016). Our contribution to this literature lies in looking at how yields and liquidity of bonds with different maturities are affected by these measures and how this could lead to structural distortions of the yield curve.

We also consider the second reason for differences. In a well-functioning market, distortions local to certain maturities could be traded away by arbitrageurs constantly searching for such mispricing to profit from. However, market frictions, for instance margins, haircuts and other constraints, might prevent such investors from trading on these inefficiencies, as the limits of arbitrage literature describes (Shleifer and Vishny, 1997; Gromb and Vayanos, 2002; Liu et al., 2006; Gorton and Metrick, 2010; Ashcraft et al., 2010). Additionally, arbitrage capital might move too slowly to eliminate such opportunities, due to capital constraints or agency problems of delegated asset management, as in Mitchell et al. (2007) or in Duffie (2010).

The third driver leading to differential pricing could be alternate levels of risk premiums in short and long term yields. We consider the following premiums in our analysis: flight-to-safety premium, liquidity premium, credit risk premium and partial default or breakup risk premium. We study whether short and long maturity bonds have different sensitivity to flight-to-safety flows. These episodes occur when due to a credit shock, investors reallocate their portfolios towards safer assets. This can happen both within, as well as across asset classes (Næs et al., 2011) and is typically accompanied by flights-to-liquidity (Longstaff, 2004). Beber et al. (2009) disentangle flight-to-safety and liquidity episodes using a sample of Eurozone bonds from 10 countries, whereas Baele 
et al. (2015) develop a methodology to identify such episodes in a sample of 23 countries. Ejsing et al. (2012) identify safe haven flows in German and French bond markets. We also provide evidence that when periphery credit quality declines in the Eurozone, the overall German yield curve becomes a target for such flows, as investors exhibit a stronger preferece for credit quality than for bond maturity.

Further, our paper contributes to the existing literature on liquidity and the term structure of liquidity premium in bonds. Liquidity premium of government bonds can be analyzed along two dimensions. Early studies typically estimate liquidity premium by identifying pairs of assets that are otherwise similar, but have different levels of liquidity. These assets can either have the same issuer and differ in their seasonedness (Krishnamurthy, 2002; Gürkaynak et al., 2007; Bühler and Vonhoff, 2011; Schuster and Uhrig-Homburg, 2013; Kempf et al., 2012; Fontaine and Garcia, 2012) or provide the same guarantees while being issued by different institutions (Longstaff, 2004; Krishnamurthy and Vissing-Jorgensen, 2011; Schuster and Uhrig-Homburg, 2013; Schwarz, 2015). However, this latter measure is often criticized as it not only captures liquidity premium, but also breakup or partial default risk.

Much less is known about liquidity differences in the cross-section of different bond tenors, especially of the very long maturities. Most papers that study this question focus on the US corporate bond market: Ericsson and Renault (2006) find a decreasing term structure, while Dick-Nielsen et al. (2012) find that liquidity premium increases with maturity. Gehde-Trapp et al. (2018) provide a third view: they find a U-shaped premium, where the very short and very long maturities carry the largest compensation for illiquidity. Goyenko et al. (2011) study liquidity premium differences and explain the on- and off-the-run premiums of three maturity buckets: short maturity T-bills, and 2-5 year and 10-year bonds. Despite its practical importance, the long end of the term structure has attracted much less attention in academic research. We aim to fill this gap, by showing how yields and liquidity can substantially differ among longer and shorter maturities of nominal German sovereign bonds. 
This paper also relates to the strand of literature that separates liquidity and credit effect in sovereign yields. Beber et al. (2009) disentangle the effects of liquidity and credit quality in 10 Eurozone countries. Similarly, Schwarz (2015) separates the components of yields due to liquidity and sovereign risk. Ejsing et al. (2012) quantify liquidity and sovereign risk premiums in German and French government bond yields based on a state-space model with two latent factors. Bai et al. (2012) examine what caused the recent sovereign bond crisis - illiquidity of markets or deteriorating credit conditions. Darbha and Dufour (2014) study the term structure of default and illiquidity in a sample of nominal Euro area government bonds, whereas Monfort and Renne (2014) present an arbitrage-free model with joint dynamics of euro-area bond spreads that are driven by liquidity and sovereign risk. Besides, we not only consider the sovereign risk of the issuer, but test for breakup or partial default risk component in German yields, as in De Santis (2015) and Simon (2015).

And finally, our work closest relates to the recent papers of Greenwood and Vissing-Jorgensen (2018) and Christensen et al. (2018). Greenwood and Vissing-Jorgensen (2018) study the effect of the pension and insurance industries (P\&I) on the yield curve, more specifically the yield spread between 10 and 30-year bonds. Using a cross-country sample, they find that in countries with large $\mathrm{P} \& \mathrm{I}$ the spread is smaller, indicating that the preferred habitat demand of these institutions supresses yields of long maturity bonds. In event studies they document that when regulators reduce the dependence of the regulatory discount curve on a specific security, its yield increases. They find that the largest distortions are for Scandinavian countries, while we study the very liquid German market. Nevertheless the argument on the LLP is similar to our discussion in Section 6.3., as well as to the results of Christensen et al. (2018). They show that extrapolating long-maturity bond yields by means of a dynamic Nelson-Siegel method produces reasonable discount rates, which are in line with predictions of professional forecasters, therefore fit for regulatory valuation. This argument and our findings confirm that extrapolating from long-term yields could reduce the demand and price pressure on the LLP, and as such, alleviate the concern raised by Greenwood and Vissing-Jorgensen (2018). 


\section{Bond market segmentation}

The expectations hypothesis of the term structure (EHTS) postulates that risk premiums on long-term bonds, the expected excess returns of long maturity bonds over short ones, should be constant over time. If EHTS holds, risk premiums would not vary over time. Consequently, as Pflueger and Viceira (2011) point out, investors could not earn predictable returns on switching between long and short maturities. As such, bonds of short and long maturities should be close to perfect substitutes and the shape of the yield curve should only depend on investors' expectation of future rates.

However, there is ample evidence of predictable and time-varying risk premiums in bonds (Bliss and Fama, 1987; Cochrane and Piazzesi, 2005; Pflueger and Viceira, 2015). Moreover, in practice, different maturities are not perfect substitutes due to the presence of investor clienteles with preferences for specific maturities. As a consequence, the interest rate for a given maturity is also influenced by demand and supply shocks specific to that maturity. Vayanos and Vila (2009) show that if investors have preferences for certain maturities, bond markets become segmented. Additional evidence for the presence of preferred habitat investors is presented by Greenwood and Vayanos (2010), who find that the average maturity of government debt predicts excess bond returns. On the other hand, Guibaud et al. (2013) show that catering to maturity clienteles is an optimal issuance policy, as a welfare-maximizing government issues longer maturity debt when the fraction of long to short horizon investors increases. Additional evidence suggests that corporations n] and Eurozone governments engage in gap-filling behavior, issuing long-term debt at times when the supply of long-term government debt decreases (Greenwood et al., 2015; Eidam, 2017).

In light of this evidence, we think that segmentation is a result of either regulatory constraints or endogenous choice to hold only a part of the yield curve. Prominent examples of such regulation are the Basel and Solvency regulatory frameworks that incentivize banks, insurers and pension funds to tilt their asset portfolios towards certain 
maturities. On the other hand, clienteles can also arise due to the costs of trading or investors' holding period. Amihud and Mendelson (1986) show that investors with different holding periods trade assets with different relative spreads, whereas the recent work of Beber et al. (2012) show that in the presence of investors with heterogeneous investment horizons, the pricing of liquidity also becomes segmented. In segmented market, short and long maturity bonds are not perfect substitutes and therefore investors cannot achieve the same risk exposures by holding only certain bond tenors. This would be otherwise in integrated markets, where all parts of the market are spanned by the same risk factors. We aim to discover the extent to which German sovereign bonds are subject to segmentation and the channels through which this affects the pricing of short and long maturity bonds. More specifically, we are interested in whether segmentation implies pricing differences along the yield curve, and if so, their underlying drivers. We also examine how liquidity of long and short bonds differs and whether they it is priced differently.

\subsection{Segmentation in observable yields}

In integrated markets, where risk premiums are the same along the yield curve, a term structure model fitted on observable yields would have an equally good fit across different maturities. However, if markets are segmented, we are likely to observe larger fitting errors on the part of the curve where yields are most distorted by segmentation. These fitting errors are a good measure for structural distortions and are used in this study to proxy for segmentation in long maturity bonds. We define the bias as the average fitting error of long maturity bond yields compared to the Nelson-Siegel curve that we estimate from yields of German sovereign capital market securities. ${ }^{4}$ The idea of using the quality of fit to proxy for segmentation is similar to that of HPW, who show that the mean squared fitting error effectively proxies for market liquidity closely linked to the available arbitrage capital and funding liquidity dry ups around crises.

\footnotetext{
${ }^{4}$ The detailed description of how this measure is constructed can be found in Section 4 .
} 
We analyze whether the size and sign of this structural distortion in yields (bias) varies over time, depending on the forces that drive the short and long ends of the yields curve. To measure the differential effect of these drivers, we separately decompose short and long yields in our sample. Our yield decomposition is inspired by Krishnamurthy et al. (2018), henceforth KNVJ, who show that yields of Eurozone sovereign yields are composed of an expectations hypothesis term and term premium, default risk premium, redenomination risk premium, and a residual term that arises due to illiquidity frictions. While focusing on differences between short and long yields, we expand the list of potential yield components. We take a broader view on segmentation and liquidity frictions by incorporating demand pressure, default premium and the differential liquidity of short and long-term bonds.

Demand pressure can arise due to regulatory changes, flight-to-safety flows and as a product of unconventional monetary policies, such as LSAPs and QE. First, regulatory changes matter if they affect only part of the investor clientele. For instance, the Basel III capital regulation of the banking sector incentivizes banks to hold shorter term government bonds in their investment portfolios. Although all sovereign bonds bear the same risk weight, shorter maturities can be used for trading and derivative settlement more often. As opposed to this, Solvency II focuses on asset and liability management of pension funds and insurers. Since these institutions have long-term liabilities, which have to be hedged by minimizing the duration gap between assets and liabilities, the regulation incentivizes to hold bonds with maturities longer than 20 years. To (indirectly) capture the effect of regulatory demand pressure, we include a time trend in our analysis. The second channel of demand pressure arises during the financial and euro crisis, when investors are flying to safe haven assets from the riskier periphery bonds. We capture this effect by a variable linked to changes in the default risk of Eurozone periphery sovereign issuers. And at last, the unconventional monetary policy measures applied during the fore mentioned crises have an effect on bonds that are part of the policies of the European Central bank (ECB), such as the Securities Markets Programme, the Outright Monetary Transactions, and the Long-Term Refinancing Operations. To capture the sum of these 
monetary policy actions, we control for the growth of the asset side of the ECB's balance sheet.

Similar to KNVJ, we also differentiate between two types of default risk premium. Segmentation could also result in a differential effect of sovereign risk on the short and long ends of the yield curve. We proxy issuer credit risk by the 5-year USD-denominated German CDS spread. Despite that Klinger and Lando (2018) show that the CDS spread of a safe haven country, like Germany, is a poor proxy for its credit risk due to regulatory hedging requirements of investment banks, this is consensually the best proxy for sovereign risk. Nevertheless, we also consider breakup and selective default risks. We define selective default, as the government strategically defaulting on certain type of obligations, affecting only certain clientele groups. For instance, in case of insolvency the government could default exclusively on short maturity bonds, as they are due in the near future, while keeping promises on long maturity bonds - mostly held by institutional investors. Selectively defaulting on bonds could also result in the exit from the Eurozone, a scenario in which the sovereign issuer would fulfill obligations in a currency other than in euros. This constitutes a risk for investors, who as a consequence would be paid in a depreciated currency. This redenomination risk is closely linked to selective default and a direct consequence of the breakup of the Eurozone. We capture selective default and breakup risk by the KfW spread from Schwarz (2015), defined as the yield difference between the 10-year KfW agency bond and the German Bund of matching maturity. Simon (2015) shows that if investors expect the occurrence of selective default, a risk premium in yields arises.

\subsection{Segmentation effects in bond liquidity}

Vayanos and Vila (2009) show that if investors have preferences for certain maturities, bond markets become segmented. Investors may choose to hold only a part of the yield curve due to either regulatory constraints or endogenously, which is either due to the costs 
of trading or the holding period. Amihud and Mendelson (1986) show that investors with different holding periods trade assets with different relative spreads.

Liquidity segmentation arises when investors have different holding periods, but its effect that goes beyond relative trading costs. Beber et al. (2012) show that if investors have different investment horizons, liquidity also becomes segmented. This has an effect on the pricing of liquidity, as accounting for investment horizon gives rise to cross-sectional differences in liquidity risk premiums. Moreover, it is also plausible that for investors with different horizons, different aspects of liquidity would matter: we find that our short and long noise measures are primarily driven by different aspects of asset, market liquidity and liquidity risk. We provide further evidence for the effect of segmentation on liquidity based on the noise measures for the long and short ends of the curve. Although our bond sample does not allow for formal cross-sectional pricing tests of liquidity, we can investigate the exposures of yields of short and long maturity bonds to the segmented noise measures in the time series context. We also test for liquidity spillovers between the two ends of the yield curve.

As part of our analysis, we link the segmented noise measures to various proxies of liquidity to shed light on its differential nature along the yield curve. It is conceivable that due to investment horizons, the aspect of liquidity that we capture will differ across shorter and long maturities. On the one hand, an investor with longer holding periods is not concerned about transaction costs per se, since they do not trade frequently. Taking this to the extreme, a buy-and-hold investor should not be concerned about liquidity risk either, as unless she has to liquidate, she will hold that asset until maturity. On the other hand, actively managed portfolios have to be rebalanced regularly. These investors will have a preference for more liquid and cheaper to trade assets, moreover, they will be more exposed to dry ups of market and funding liquidity. We link the segmented measures of liquidity to other measures of market distress, volatility and default risk and test whether short and long end liquidity correlate with these proxies to a different extent. 


\subsection{Why German sovereign bonds?}

To discover the effects of market segmentation on yields and liquidity, we focus on German government securities between 2005 and 2015. This period is characterized by the financial crisis, a major liquidity event; and the euro crisis, a time period when Germany became a safe haven in the euro area. Moreover, a harmonized regulatory reform affecting the natural clientele of these securities also takes place in this period, characterized by the preparatory phase of Solvency II. ${ }^{5}$ Additionally, German bonds have been subject to large scale purchase programs improving market liquidity, and since the beginning of 2015 also to the quantitative easing (henceforth QE) of the European Central Bank. Thus in the past ten years we are likely to observe investor segmentation (preferred habitat or clientele), regulation-induced demand pressure, the effect of LSAP and QE on yields, alongside with flight-to-safety episodes. These events might have a differential effect on long and short maturity bonds, and their confounding presence makes the German sovereign bond market an ideal testing ground to study our research question.

\section{Measuring the effect of market segmentation}

\subsection{The data}

The data come from multiple sources. Daily closing mid quotes of German capital market securities, bond characteristics, credit default swap (CDS) quotes, and quotes of EONIA and Euro swap contracts of different maturities are from Bloomberg. The aggregate size of the asset side of ECB's balance sheet also comes from the same source. This information is complemented with $\mathrm{KfW}^{6}$ agency bond quotes from Datastream, Ted spread and VIX

\footnotetext{
${ }^{5}$ The Solvency II Directive codifies and harmonizes regulation of insurers and pension funds in the European Union. Its main concern is similar to that of the Basel banking regulatory framework, it regulates the amount of capital insurers and pension funds are obliged to have as reserves to decrease the risk of insolvency. Solvency II also has risk management and governance considerations, along with consumer protection, transparency and disclosure requirements.

${ }^{6} \mathrm{KfW}$ or Kreditanstalt für Wiederaufbau is a German government-owned development bank in Frankfurt. Its majority owner if the Federal Republic of Germany, which explicitly guarantees bonds
} 
from the FRED database of the St. Louis Fed and the value of the DAX index from the Deutsche Bundesbank. We also use data provided by the Deutsche Finanzagentur $\mathrm{GmbH}^{7}$ on aggregate primary dealer transaction volumes.

The starting point to measure the effect of market segmentation is the noise measure, which we construct from daily cross-sections of bond returns from 2005 through 2015.We focus on segmentation in yields, as well as in liquidity along the yield curve; therefore, we use all German sovereign nominal capital market securities in our analysis. Bonds in our sample have fixed maturities and coupons, the same market conventions and microstructure; and can be assigned to one of the three groups: 2-year notes (Schaetze), 5-year notes (Bobls), and 10 or 30-year Bunds. Similar to other studies, we drop bonds with less than 6 months to maturity due to liquidity problems, however, we do not impose an upper bound on time to maturity. This is because we are specifically interested in how yields of long maturity bonds differ from their shorter counterparts and whether different market forces drive them.

In the resulting sample we have, on average, a cross-section of 52 bonds, out of which about 5 bonds are of maturities longer than 20 years. However, the cross-section varies over time, ranging between 41 and 61 issues of capital market securities, and 1 to 8 long maturity bonds at a time. The average maturity of bonds is 8.34 years, whereas their average age is 8.71 . These values remain relatively stable in the sample, alleviating the concern that our result would be driven by the time series variation of bond characteristics. Nevertheless, in our analysis we control for bond maturity. The average coupon is $2.97 \%$, with a standard deviation of $1.82 \%$ and maturity dates of bonds range between February 2005 and August 2046.

\footnotetext{
KfW issues in capital markets.

${ }^{7}$ German Finance Agency, the German equivalent of the U.S. Treasury.
} 


\subsection{German sovereign bond market}

The Federal Government of Germany is one of the largest issuer of government securities in the Eurozone. These securities are not only highly liquid; they also carry small issuer risk and preserved their triple-A rating even during the Euro crisis. German government bonds have maturities from 6 months to 30 years, which span the entire yield curve with 60-70 tradable securities at any point in time. Capital market securities consist of three types: Federal Treasury notes (Schaetze), Federal notes (Bobls) and Federal bonds (Bunds) with the fore mentioned maturities ranging between 2 and 30 years. $^{8}$

German sovereign bonds are typically placed to bidding group members, similar to U.S. primary dealers, in the form of single issues via auctions, which can be followed by multiple re-openings to keep the market liquid and to facilitate delivery of futures contracts on these bonds.. The average outstanding volume of a single issue is around $€ 15-20$ billion. The relative share of each security type is stable over time: 2-year notes constitute $9 \%$, 5-year notes 21\%, 10 years Bunds 44,5\% and 30 year Bunds $17 \%$ of the overall public debt issued by the Federal Government in 2015. This means that our sample covers about $90 \%$ of all German tradable government debt (stock), and about $70 \%$ of the total issuance (flow). All capital market securities have fixed maturities with redemption on maturity at the full nominal value, as well as annual fixed interest payments. These assets are also repo and ECB-eligible, moreover, Bunds are strippable. ${ }^{9}$

\subsection{Curve fitting}

To fit the term structure of interest rates, the two most common approaches are the estimation of either spline-based or function-based models. The latter is a parsimonious parametric function that describes the entire yield curve. We choose to work with the

\footnotetext{
${ }^{8}$ Since 2006, the Federal Government has also been issuing inflation-linked securities, but in this study we restrict our focus to nominal bonds.

${ }^{9}$ We believe that this feature does not give rise to a large enough convenience yield in the respective bonds that this would distort our results.
} 
model of Nelson and Siegel (1987), which provides a smooth, flexible parametric function. As De Pooter (2007) describes, this model is capable of capturing many of the typically observed shapes ${ }^{10}$ that the yield curve can take over time. The Nelson-Siegel model assumes the following functional form for the instantaneous forward rate f:

$$
f(m, b)=\beta_{0}+\beta_{1} \exp \left(-\frac{m}{\tau}\right)+\beta_{2}\left(\frac{m}{\tau}\right) \exp \left(-\frac{m}{\tau}\right)
$$

where $m$ denotes time to maturity and $b=\left(\beta_{0}, \beta_{1}, \beta_{2}, \tau\right)$ are model parameters to be estimated. The three elements of the above sum have a clear interpretation: $\beta_{0}$ is the long term component, which is the same for every maturity; the component on $\beta_{1}$ is the short term component, which starts at 1 and decays to zero at an exponential rate; whereas the one on $\beta_{2}$ is the middle-term component, which can generate hump shapes of the yield curve. $\tau$ is a time invariant constant, which determines at which maturity the middle-term component reaches its maximum. Additionally, Diebold and Li (2006) show that the three betas can be interpreted as dynamic latent factors, governing the level, slope and curvature of the yield curve.

Following HPW, we use the parameterized forward curve of Equation 1 to derive the corresponding zero-coupon yield curve. This can be used to price any coupon-bearing bonds. Consequently, we can use market prices of bonds to back out the parameters in $b$. In particular, on each day of our sample we estimate the model from observable market prices of German notes and bonds in our sample with remaining maturities between 6 months and 20 years. This results in a vector of parameters on that day, based on which we can predict the theoretical values of the observed bonds. In order to fit the model, we choose parameters $b_{t}$ by minimizing the weighted sum of squared deviations between the observable and the model implied prices:

$$
b_{t}=\underset{b}{\operatorname{argmin}} \sum_{i=1}^{N_{t}}\left[\left(P^{i}(b)-P_{t}^{i}\right) \times \frac{1}{D_{i}}\right]^{2},
$$

\footnotetext{
${ }^{10}$ Which are monotonic, humped and S-shaped.
} 
where $N_{t}$ is the number of bonds for a given day, $P_{t}$ are the prices observable on the market, whereas $P^{i}(b)$ is the model-implied price for bond $i$ given the model parameters $b$, and $D_{i}$ is the MaCaulay's duration for bond $i$. Following literature, we apply duration-weighting to bonds when estimating the parameters that minimize their pricing errors.

In fact, one deviation from the approach of HPW is that we do not estimate all parameters in Equation 1 freely, but keep $\tau$ fixed for the analysis. In preliminary unrestricted estimations, $\tau$ turns out to be badly identified with very extreme values on days when the yield curve is flat. This suggests multicollinearity of the parameters, thus we decided to fix $\tau$ at its the median value (2.58) based on the preliminary unrestricted estimation of the model. Keeping $\tau$ fixed, we re-estimate the rest of the parameters to obtain the fitted curves for each day in our sample. ${ }^{11}$

Figure 1 depicts the fitted par-coupon curves and the observable yields for three days in our sample: January 3, 2005, September 15, 2008 and February 23, 2015. The left panels depict the short end of the yield curve, bonds with less than 20 years to maturity to which the curve is fitted; whereas the right panels show maturities longer than 20 years. For these bonds we extrapolate the fitted curve, thus the long end serves as an out-sample test of fit. The first day is a 'normal day', we can see that the short end on the curve fits rather well to the increasing term structure, while in the long end the deviations are larger, around 10-15 basis points. For the day of the Lehman bankruptcy, September 15, 2008, fitting errors on both the short and long ends are larger, so are they some days after the announcement of the quantitative easing of ECB on February 23, 2015.

\subsection{Measures of noise}

To construct the noise measure, we follow HPW. For each day in the sample, given a set of parameters $b_{t}$ from Equation 2, we calculate the difference between the fitted and

\footnotetext{
${ }^{11}$ Although we conduct most of our analysis keeping $\tau$ fixed, we find that results are highly similar when we use a completely unrestricted estimation allowing $\tau$ to vary daily. Nevertheless, we added a robustness section, where we show how sensitive the resulting noise ad bias estimates are to different values of $\tau$, e.g. half, twice or ten times the unconditional mean value.
} 
observable market yields. HPW define noise as the dispersion of yields around the (entire) fitted yield curve, which is measured as the root mean squared pricing error in a given cross-section of bonds. Our approach differs in that we want to focus on the shorter and long ends of the curve separately. Consequently, we construct two sets of noise measures the following way.

For each date $t$, let $b_{t}$ be a vector of parameters with $\tau=2.58$. On the given date $t$, there are $N_{\text {short, } t}$ notes and bonds in our sample with maturities between 6 month and 20 years and $N_{\text {long,t }}$ bonds with remaining maturities exceeding 20 years. Then for each of these bonds part of $N_{\text {short }, t}$ and $N_{\text {long, } t}$, we calculate the difference between $y_{t}^{i}$ and $y^{i}\left(b_{t}\right)$, the observed market and the model-implied yields, respectively. Then we define noise as the dispersion around the given segment of the fitted curve, which we measure as the root mean squared pricing error of the short and long ends of the yield curve separately:

$$
\begin{gathered}
\text { Noise }_{\text {short }, t}=\sqrt{\frac{1}{N_{\text {short }, t}} \sum_{i=1}^{N_{\text {short }, t}}\left[y_{t}^{\text {short }, i}-y^{\text {short }, i}\left(b_{t}\right)\right]^{2}} ; \\
\text { Noise }_{\text {long }, t}=\sqrt{\frac{1}{N_{\text {long }, t}} \sum_{i=1}^{N_{\text {long }, t}}\left[y_{t}^{\text {long }, i}-y^{\text {long }, i}\left(b_{t}\right)\right]^{2}}
\end{gathered}
$$

We fit the yield curve to bonds with maturities between 6 months to 20 years, but we construct the noise measure for bonds with a wider range of maturities. Consequently, the noise measure of the longer end also serves as 'out-of-sample' test of the fitted curves. Our choice of the 20-year breakpoint is not arbitrary; it comes from the ultimate forward rate discussion of Solvency II. The ultimate forward rate is an extrapolation method that used to calculate long term discount rates used in valuation of liabilities for regulatory purposes for bond maturities that lie beyond the last liquid point. This point for euro-denominated interest rates is set at 20 years-to-maturity. Consequently, there could be structural distortions due to liquidity, market segmentation, demand pressure and differences in default premium across the curve. This is one of the questions we aim to answer in this 
paper.

Table 1 presents summary statistics for the noise measures, whereas Figures 2 and 3 depict the different noise measures. Panels A and B of Table 1 and Figure 2 focus on the noise measures of the short and long ends of the yield curve. The average short noise is 7.91 basis points between 2005 and 2015, whereas the long average is 19.39 basis points. In the long end, the standard deviation of noise is also larger. The maximum value of noise is 20.46 bps in the short, and 49.58 bps in the long end. Figure 2 shows that the magnitude of noise varies over time, with large peaks around the financial and euro crises. Long yields have a poorer fit during this period, and thus noise is persistently high. However, this fit is still much better than what the regulatory discussion (on ultimate forward rates) considers as a starting point, especially given our simple curve fitting method.

Figure 3 compares our measures to that of HPW. Panel $\mathrm{C}$ of Table 1 also gives the descriptive statistics for the US noise measure. Its mean is 3.1 basis points with the range 0.72 to 20 basis points. The three measure exhibit a large spike at the financial crisis, but the US measure goes back to near zero afterwards, whereas the German measures, in reaction to the euro crisis, fluctuate at higher levels. However, these three measures are not fully comparable due to their different composition and methodological choices. First, HPW fit their model to bonds of maturities shorter than 10 years, also including T-bills in their analysis. Noise is calculated for a somewhat smaller set of bonds and averaged over the whole curve. As opposed to this, we exclusively focus on notes and bonds. We fit the yield curve to bonds with maturities up to 20 years, but part of our analysis focuses on issues with even longer tenors. Noise is also separately calculated for short and longer maturity bonds. Second, due to our smaller cross-section of bonds we choose to fit a Nelson-Siegel curve, whereas HPW use the more elaborate Svensson method. Despite the differences, our noise measures are proxies for market illiquidity, which show how prices deviate from fundamentals. To demonstrate this, the next section presents the link of noise measures to various asset level and market liquidity proxies. 


\subsection{Do German noise measures capture illiquidity?}

HPW show that the noise measure is a proxy for market-wide liquidity that is related to the arbitrage capital available: the pricing error is larger and more persistent when funding liquidity conditions deteriorate and arbitrageurs lack resources to trade substantial price deviations away. To this extent, this, as well as our measure captures funding liquidity, as in Brunnermeier and Pedersen (2009) or Fontaine and Garcia (2012).

Table 2 reports the results of monthly regressions of changes (first differences) in short and long noise measures separately, regressed on a series of asset and market level liquidity proxies. Panel A shows that changes in the short end noise measure are linked to changing age of the bond. One standard deviation decrease in time to maturity, or the bond gets 30 days older, increases the noise by 0.67 basis points. That is, that the older the bonds gets, the more likely it gets locked up in buy-and-hold investors' portfolios, which decreases the issue's liquidity, which in turn increases deviation from the theoretical yield. Similarly, short noise is linked to the changes in on-the-run spread of 10-year bonds and the Ted spread, with smaller but positive economic effects, in 0.29 and 0.38 basis points increases, respectively. This suggests that as the level of market liquidity or funding conditions worsen, noise tends to increase.

Panel B shows that the noise of long maturity bonds increases with the proportion of zero returns. If zero returns change by $0.63 \%$, the noise increase 0.56 basis points. As for market liquidity proxies, long noise significantly links to noise from the US, which is a crisis-related aspect of funding liquidity. If US noise changes by one standard deviation, noise of German long maturity sovereign bonds increases by 0.91 basis points. Interestingly, the measures are not related to the implied bid-ask spread of Roll (1984) or to liquidity risk measured as the unexpected changes of the ILLIQ measure of the German nominal bonds market. However, even the statistically significant connections are not very strong as the $\mathrm{R}^{2}$ of these regressions are rather low. HPW find similarly weak links to other measures of liquidity, which they argue is an indication of noise capturing 
an aspect of liquidity beyond the typical measures used in the literature.

To summarize, we find that our measures of noise from the short and long ends of the yield curve capture somewhat different aspects of liquidity. Short noise is related to the age of the bond, as well as to market and funding liquidity; while long noise is linked to asset level illiquidity (zero returns) and the US noise measure. Nevertheless, similar to HPW, we find that even these statistically significant relationships have low explanatory power, which suggests that noise captures an aspect of illiquidity that correlates, but goes beyond conventional measures.

\section{Segmentation effects: empirical evidence}

\subsection{The bias}

To examine whether the long end of the German yield curve exhibits structural distortions that could result from market segmentation, we look at the average pricing error of long maturity bonds. This distortion we call the bias:

$$
\operatorname{Bias}_{t}=\frac{1}{N_{\text {long }, t}} \sum_{i=1}^{N_{\text {long }, t}}\left[y_{t}^{\text {long }, i}-y^{\text {long }, i}\left(b_{t}\right)\right] .
$$

The bias is the average of differences between the observed, $y_{t}^{\text {long, } i}$, and model implied yields, $y^{\text {long, } i}\left(b_{t}\right)$, of bond issues with maturities exceeding 20 years.

Panel D of Table 1 reports the descriptive statistics of the bias, while the two panles of Figure 4 depict the overall bias, and its decomposition to the maturity buckets of 20-25 and $25+$ years. Table 1 suggests that the average bias throughout the sample period is negative, -9.25 basis points, and ranges between -47 basis points to 25.74 . Interestingly, it switches sign twice around the financial crisis, but stays persistently negative for the rest of the sample period. Figure 4 shows that the bias is not only negative after the financial crisis, but this effects is even more pronounced for the $25+$ years to maturity 
bucket. Nevertheless, the figure does not indicate a clear trend which could result from, for instance, regulation-induced demand pressure.

According to Equation 5, negative bias means that the observed yields are consistently lower than those implied by our pricing model. Could this be because those yields are distorted by demand pressure of clientele investors, or flight-to-safety, liquidity or credit risk premiums? To provide answer to this question, Table 3 presents evidence of the results of monthly regressions (of first differences) in which we link the bias to asset and market level liquidity measures, proxies for demand pressure, default risk, both in a uni-, and multivariate setting.

According to Panel A of Table 3, the bias correlates with bond level liquidity proxies, namely the Roll measure and time to maturity are both statistically and economically significant. If change in Roll's implied bid-ask spread increases by one standard deviation (bond liquidity decreases), the bias gets larger by 0.91 basis points. Similarly, if a bond gets one month older, the bias grows by 0.75 basis points. The bias is also linked to changes in liquidity risk and flight-to-safety flows. Liquidity risk is measured as the surprise component of the monthly ILLIQ measure of the German nominal sovereign bond segment, while flight-to-safety flows are proxied by first prinicple component (PCA) of CDS spreads of Eurozone periphery countries. We see that as credit or default risk of periphery countries increases (by one standard deviation), long maturity bond yields get 2.59 basis point further from the predicted smooth curve. Similarly, the bias reacts to changes in German credit risk, as well as to changes in volatility or investor sentiment captured by the VIX index.

Panel B of Table 3 presents the results of multivariate analysis. Column 1 pools all asset and market level liquidity proxies. The Roll measure is still significant with an even larger economic effect (1.33 basis points), while time to maturity and liquidity risks are not robust to the inclusion of the US noise measure. This implies that as US funding conditions worsen (pricing errors on Treasuries grow), the bias on German long maturity bonds also get wider. Column 2 looks at variables of demand pressure, default risk and 
volatility combined, out of which German CDS seems to matter the most. If the German CDS spread increases by 7.24 basis points, the bias also increases by 1.28 basis points. And finally, Column 3 pools all variables, and finds that the Roll implied bid-ask spread stays significant with an effect size comparable to previous cases (1.31 bps), while the Ted spread is also significant, but with a sign opposing our expectations.

All in all, we find that the bias, on average, is negative. This means that the observed yields are consistently below those implied by our model. In search for causes, we consider various proxies for demand pressure of clientele investors, flight-to-safety, liquidity and credit risk premiums. We find that the bias is linked to the Roll implied bid-ask spread, time to maturity of bonds, liquidity risk, flight-to-safety flows and the credit risk of Germany in a univariate setting. If considered in multivariate regressions, the Roll measure, German CDS and Ted spread are robust to the inclusion of other varables. In the next section we further analyze why long yields are "too low" by looking at differences in drivers of yields of short and long maturity bonds.

\subsection{Decomposing short and long maturity yields}

If due to regulation, institutional features or a given holding period, certain investors have limited access to the yield curve, this creates clientele demand specific to some bond maturities. Alongside with this, safe haven flows during the Euro crisis or large scale asset purchases of central banks and ECB can also put demand pressure on certain parts of the curve. Should these phenomena coexist with market frictions that limit arbitrage capital flows, these effects can persistently distort the part of the yield curve where it has the most prevalent effect.

Ideally one would test the influence of the above channels by formal cross-sectional pricing tests, but the data at hand, especially the small cross-section of long maturity bonds, does not grant us sufficient power for identification. As the second best solution, we investigate the exposures of yields of short and long maturity bonds in the time series. 
Our yield decomposition is inspired by Krishnamurthy et al. (2018). In their analysis, yields of Eurozone sovereigns contain the following distinguishable components: a risk free component, term premium, default risk premium, redenomination risk premium and a residual term that arises due to illiquidity frictions and segmentation. Taking their idea to our data, the following equation arises:

$$
\begin{aligned}
\text { yield }_{i, t}= & \frac{1}{T} \int_{s}^{s+T} \mathbb{E}\left[r_{s}\right] d t+\text { Term pr }_{\cdot i, t}+ \\
& + \text { Liq. pr } r_{\cdot i, t}+\text { Demand pr } r_{\cdot i, t}+\text { Default pr } r_{\cdot i, t}+\text { Controls }_{i, t}
\end{aligned}
$$

where yields are explained by a risk free component based on the expectations hypothesis, a term premium and components that test segmentation of yields and liquidity with additional controls. The idea behind this decomposition is that it allows for separate examination of long and short yields, moreover, the two sets of regressions coefficients are directly comparable.

To capture the first two components, we construct the risk free curve as the intersection of the EONIA overnight swap and euro swap curves. In our regressions we regress the average residual yields, the average of the difference between these two components and the observable yields from the market, on measures of demand pressure, default premium, liquidity and other controls We proxy for demand pressure by including a time trend to capture regulatory changes; a variable capturing safe haven flows, derived from CDS of distressed Eurozone countries; and the percentage growth of the asset side of ECB's balance sheet to control for LSAP and the effects of QE. We also decompose the default premium component to the credit risk of the issuer, captured by the German CDS spread, and to breakup risk proxied by the KfW spread. This latter controls for selective default premium, in which case the German government would default only on a set of its obligations, e.g. agency bonds or certain maturities. To show the robustness of our results, we also include additional controls, such as measures of market liquidity, the time-series of the average time-to-maturity for daily cross-sections, as well as the US noise measure. In additition, we also examine whether there are liquidity spillovers 
between the short and long ends of the term structure by adding the respective noise measures to the regressions.

The resulting empirical relationships for the average short and long residual yields are the following:

$$
\begin{aligned}
\Delta\left[\overline{\text { yield }_{\text {short }, t}}-\overline{\text { swap rate }_{t}}\right]= & \beta_{0}+\beta_{1} \Delta \text { Noise }_{t}^{\text {short }}+\beta_{2} \text { Time trend }+\beta_{3} \Delta \text { ECB } \text { Asset }_{t}+ \\
& +\beta_{4} \Delta F T S+\beta_{5} \Delta \text { Issuer credit risk }+\beta_{6} \Delta \text { Breakup risk }+ \\
& +\beta_{7} \Delta \text { Noise }_{t}^{\text {long }}+B \cdot \text { Control }_{t}+\varepsilon_{t}
\end{aligned}
$$

and

$$
\begin{aligned}
\Delta\left[\overline{\text { yield }_{\text {long }, t}}-\overline{\text { swap rate }_{t}}\right]= & \beta_{0}+\beta_{1} \Delta \text { Noise }_{t}^{\text {long }}+\beta_{2} \text { Time trend }+\beta_{3} \Delta E C B \text { Asset }_{t}+ \\
& +\beta_{4} \Delta F T S+\beta_{5} \Delta \text { Issuer credit risk }+\beta_{6} \Delta \text { Breakup risk }+ \\
& +\beta_{7} \Delta \text { Noise }_{t}^{\text {short }}+B \cdot \text { Controls }_{t}+\varepsilon_{t}
\end{aligned}
$$

Panels A and B of Table 4 report the results for Equations 7 and 8, respectively. Column 1 of both panels show the results without additional controls, while Column 2 includes all additional controls. At first glance, it seems that the noise measure is more important for long maturity bonds. Its effect not only survives the inclusion of other liquidity proxies and the US noise measure, but it is statistically and economically significant. One standard deviation change in the change of long noise, 4.23 basis points, leads to a shift of 1 yield basis point. The larger the pricing error (noise measure), the larger yields will be, which translates into lower prices due to illiquidity. Interestingly, the inclusion of the opposite noise measure does not affect yields on either ends of the curve: there is no evidence for liquidity spillover between the two segments.

If we look at the channels of demand pressure, we see that the time trend is insignificant with a negligible economic effect, whereas ECB asset purchase activity has an impact on shorter maturities. The effect of LSAPs is measured by the change in the natural 
logarithm of the asset side of ECB's balance sheet. It shows that $1 \%$ change in ECB asset growth decreases short yields by 0.28 basis points. This translates into an increase in bond prices, which is in line with decreased supply, providing suggestive evidence of ECB policies affecting sovereign yields. The third channel of demand pressure is flight-to-safety flows. We assume that the occurrence of these flows coincides with deteriorating credit quality of periphery and other large euro area countries. This has an effect on both short and long maturity bond yields to a similar extent. We see that one standard deviation decrease in periphery credit quality increases short and long yields by 3.02 and 2.94 basis points, respectively.

Next, we also look at whether default premium differs across short and long maturity bonds. We find that changes in the German CDS trigger a significant positive effect on yields: if the CDS changes by one standard deviation, short and long yields increase by 0.96 and 1.84 basis points, respectively. This means that as German credit quality deteriorates, yields will go up, while bond prices will decline. Nevertheless, this effect is rather small, taking into account that 1) Klinger and Lando (2018) show that safe haven CDS contracts are poor proxies for credit quality, as their demand is primarily driven by regulatory hedging requirements of investment banks 2) German CDS do increase over the euro crisis, but it stays low and stable relative to other Eurozone CDS contracts. We also examine how average yields correlate with breakup risk, as in De Santis (2015) or Simon (2015). We find that changes in the KfW spread, the yield spread on German agency and maturity-matched Treasury bonds, widens by 6.62 basis points, short yields decrease by 1.18 , whereas their long counterparts by 1.42 basis points. The negative coefficient on the spread is inconsistent with the idea of breakup risk, it rather captures a flight-to-safety premium in sovereign bonds compared to the KfW agency bonds.

Interestingly, the constant terms of both specifications are insignificant, which suggests that the above factors not only capture the driving forces of yields, but also pick up their general downward trend in the sample period. The $\mathrm{R}^{2}$ of the decomposition is almost twice as high for short maturity bonds than for long ones. Moreover, all these effects 
are robust in sign and also in magnitude to the inclusion of additional controls, like the off-the-run spread, Ted spread and liquidity risk to control for market liquidity, the US noise measure and the average time to maturity of the given yield segment. Figure 5 depicts the rolling correlation of changes in short and long yields, and provides further proof of negligible segmentation effects, as we cannot observe any major trends in the comovement of these yields. The correlation has a noticeable drop around the financial crisis, but even at its bottom it is $65 \%$, while it peaks in 2012 during the euro crisis at 93.5

Overall, the presented yield decomposition reveals little evidence of substantial segmentation in German sovereign bond markets. Short yields are mostly driven by short noise and large scale asset purchases, while both long and short yields are strongly linked to flight-to-safety flows and to German credit quality. Our results show that although there are statistically significant differences in the drivers of short and long maturity bonds, long yields are not substantially distorted by demand pressure, default or liquidity premiums.

\subsection{Yields and liquidity}

This section studies the link between yields and different market wide and maturity-specific liquidity measures. Our aim is to discover whether liquidity has a differential effect on short and long maturity bond yields. Similarly to the previous section, we cannot perform cross-sectional tests, but we study the exposures of yields to the different liquidity measures in a time series context. We also allow for liquidity spillovers between the two ends of the yield curve and scrutinize how the financial crisis, a major liquidity dry up, affected liquidity characteristics of German sovereign bonds.

Table 5 reports results of yield differences regressed on a set of segment specific and market wide liquidity measures. Panel A shows the results of bonds with less than 20 years to maturity. The average short yield is significantly related to changes in the corresponding noise measure: if short noise increases by 1.75 basis points (one std.), the average short 
yield decreases by 0.92 basis points. This effect is robust to the inclusion of a wide range of market liquidity measures, especially that of the Ted spread, although previous analysis suggested that the noise measure is also related to funding and market liquidity. Additionally, the Ted spread is highly significant, with an economic effect of 1.71 bps yield change if the spread widens by 25 basis points; alongside with a large increase in the $\mathrm{R}^{2}$ from $5 \%$ to $26 \%$ if market liquidity measures are included. Another feature of the short noise measure is that its effect on yield varies over time, as can be seen if it is interacted with an indicator variable of the financial crisis. The sign and magnitude of the coefficient of noise changes between the pre- and post-crisis and no crisis regimes: after the financial crisis changes in the short noise measure decrease average short yields (by 1.17 bps), while preceding the crisis it has a less significant, but positive coefficient, which doubles in size compared to the crisis period. Usually one would expect that yields go up when liquidity decreases, thus finding contradictory evidence over the crisis is puzzling.

Panel B focuses on liquidity of long maturity bonds. Similarly to the average short yield, the average long yield has a tie to the fitting error of long maturity bonds. This relationship is definitely weaker than that of short yields and short noise, and is not robust to the inclusion of market liquidity measures. However, the economic effect is comparable: 0.89 basis points. Besides, unlike for the average short yield, there is evidence for a liquidity spillover from the short end to the long one: if short noise increases by one standard deviation, the average long yield increases by 0.75 basis points. Interestingly the difference between the pre- and post-financial crisis periods is smaller than that of short bonds: after the crisis the long noise measure does not have a statistically significant relation with the average long yield, whereas the interaction of long noise and the pre-crisis period is borderline significant with a positive coefficient. $\mathrm{R}^{2}$ of all five specifications are low, in the range of 3 to $7 \%$.

In conclusion, we find that yields of the short and long ends of the yield curve are linked to a wide range of liquidity measures. The effect of short noise on the average short yield is statistically and economically significant and robust to the inclusion of other 
measures. Moreover, the effect of short noise varies over time in relation to the financial crisis. As opposed to this, the average long yield has a weaker connection to long noise measure, while we find evidence of liquidity spillover from the short to the long end of the yield curve. The next section further discovers variables that could drive the two noise measures.

\subsection{The effect of segmentation on liquidity}

We do not find evidence for substantial segmentation in yields, but the differential effect of long and short noise measures suggests that liquidity of the corresponding bonds is less correlated than their yields are. This low correlation could be indicative evidence of the effect of segmentation on liquidity. In this section, we provide further evidence by exploring whether these differences stem from the underlying forces that drive liquidity of each segment.

Table 6 compares how the short and long noise measures relate to demand pressure, default risk and volatility measures in Panels A and B, respectively. In previous analyses we linked the noise measures to various asset and market liquidity proxies. We find that the short noise measure captures market liquidity, which is beyond the off-the-run and Ted spreads; while the long noise seems to behave independently from other market variables. As expected, there are some differences in the exposures to the fore mentioned measures: short noise significantly correlates with flight-to-safety flows and the asset growth of the ECB's balance sheet. As the credit quality of periphery countries worsens, the change in short noise increases by 0.33 basis points. This is due to the increased demand in safe haven bonds, which pushes prices away from the theoretical value suggested by the fitted yield curve. Similarly, as ECB purchases shorter maturity German bonds, $1 \%$ growth of the ECB assets increases noise by 0.57 basis points. Panel A also suggests that noise is sensitive to volatility captured by the VIX index or the German stock market volatility index, the DAX. 
Panel B shows that the long noise measure has a similar relationship with safe haven flows as short noise. This suggests that these flows are not exclusive to certain maturities, hence the overall German yield curve becomes attractive if periphery credit quality declines. Interestingly, long noise is more exposed to changes in German credit quality or breakup risk, captured by changes in the German CDS and the KfW spread, respectively. Their economic effects are also sizable: if the CDS spread increases by 7.28 basis points, the noise on the long end of the curve increases by 1.04 basis points; while 6.62 basis point change in the KfW spread triggers a similarly sized, 1.19 basis point increase. Long noise also correlates with volatility, with an economic effect that is twice as large as that of short noise.

Figure 6 depicts the 180-day rolling correlation of changes in the short and long noise measures. Noise measures exhibit high correlation before the financial crisis and in the post-crisis recovery period. There is a significant drop during the crisis, although the correlation stays positive, unlike after 2011, where it becomes persistently negative. Similarly to the correlation between short and long maturity bond yields, we cannot see a clear pattern that would suggest a large effect of segmentation on liquidity, however this correlation has a considerably larger range of -45 to $90 \%$.

In summary, we find that the short and long noise measures are drven by different market forces: short noise is sensitive to large scale asset purchases of the ECB, as well as to changes in stock market volatility and flight-to-safety flows. The long noise measure has a similar relationship to safe haven flows, which suggests that these flows are not exclusive to certain maturities. The long noise is also sensitive to declining credit quality of the issuer, as well as to breakup risk, however all the above effects are economically small.

\subsection{Robustness tests}

In this section we aim to test how sensitive the long maturity noise and bias measures are to changing the shape parameter, of the Nelson-Siegel curve. In preliminary unrestricted 
estimations, $\tau$ is poorly identified with very extreme values on days when the yield curve is flat. Consequently, we fix $\tau$ at its the median value (2.58) and conduct most of our analysis keeping it fixed. In unreported regressions we find that results are highly similar when we use a completely unrestricted estimation of tau - allowing it to vary.

Alternatively, we could also impose structure on the shape parameter, as Quaedvlieg and Schotman (2016) propose in their paper. Any moving average or ARMA process could be applied, as long as there are no prolonged periods of days with very flat term structure. However, imposing such a structure on the shape parameter is non-trivial. On the one hand, in our sample, especially around the onset of the financial and the peak of the euro crises, we have a multitude of days with very flat term structure. On the other hand, another obstacle for implementing their procedure is that it is numerically challenging when using coupon bonds, since in this case one cannot filter out the other parameters on each day from the zero yields similarly to Quaedvlieg and Schotman (2016).

Given our data limitations, we choose a more feasible alternative, which is to show that the size and time series characteristics of the long noise measure and the bias do not depend on the choice of the shape parameter, $\tau \cdot{ }^{12}$ The four panels of Figure 7 aim to prove this point: they depict the noise and bias measures for bonds with maturities longer than 20 years, from unrestricted estimation or $\tau$ fixed at different values. First, we compare the long noise and bias measures for the taus from the unrestricted estimation and the one, where $\tau$ is fixed at its unconditional median. The upper panels of Figure 7 show that in both cases, maybe even more so for the bias, the time-series patterns are rather similar. The most significant difference is that the series based on the unrestricted estimation exhibit more spikes, those are typically days, where the numerical optimization does not converge to a global maximum.

How much our results are driven by the choice of $\tau$ ? We estimate the long noise and bias measures given different fixed levels of $\tau$. These are half of the median, the median, and

\footnotetext{
${ }^{12}$ We focus on measures of the long end as those are 'out-of-sample' tests of the curve, where deviations and thus the differences arising due to alternative values of $\tau$ are expect to be larger.
} 
twice and ten times the unconditional median. Since $\tau$ is the time invariant constant, which determines at which maturity the middle-term component reaches its maximum, we believe that our choice or at most twice the median could be reasonable values. The lower panels of Figure 7 show that even an unrealistically large $\tau, 25.8$, would not generate noise and bias measures that are inexplicably large. While the median value produces an average long noise and bias of 18.82 and -9.25 basis points, taking this extreme value leads to 50.26 and -14.77 basis points, respectively. These values still fall in the reasonable range, despite that such a $\tau$ economically would not make sense.

\section{Discussion and policy implication}

This section aims to address three issues: first, we would like to compare the extrapolated Nelson-Siegel curve to the one used by the regulator for liability valuation of pension funds and insurance firms. Second, we perform a thought experiment, in which we quantify economic effects from the asset and liability management point of view of two hypothetical pension funds with different characteristics. And lastly, we explain the European policy discussion and specify our contribution, pointing towards directions for further research.

\subsection{Regulatory vs. extrapolated Nelson-Siegel curves}

How different is the extrapolated Nelson-Siegel curve from the one used by regulators? In answering this question, we compare the ultimate forward rate (UFR) curve provided to us by the Dutch Central Bank (DNB) to the one we propose in this paper. The UFR method is an extrapolation technique to calculate long term discount rates for valuation of liabilities for regulatory purposes, for maturities beyond the last liquid point. This point for euro-denominated interest rates is set at 20 years and the curve reaches its maximum value of $4.2 \%$ well beyond 60 years. The UFR curve provided by DNB is constructed followings the guidelines provided by EIOPA, and it is based on German interest swap 
data from Bloomberg.

Figure 8 presents the comparison between the UFR and the extrapolated curve we fitted on German bond data. The upper panel depicts the UFR curve as it has been provided by the DNB. It is immediately apparent that fitting the curve on swap rates gives rise to an approximate 35 basis point differential between the two term structures. This is most likely the sum of compensation for counterparty risk in bilateral swap transactions, and illiquidity of different contracts maturities. Nevertheless, this differential seems to widen especially beyond the last liquid point, where our market-based estimates for long term yields are much lower than their swap-based UFR counterparts. To confirm this increase in the difference, the lower panel shows the same Nelson-Siegel curve together

with the UFR curve net of the swap premium. The assumption underlying the swap premium correction is that the counterparty and liquidity risks are independent of the contract's maturity. We define the swap premium as the average difference between the NS curve fitted on bond data and the UFR curve based on swap data up to 20 years to maturity. The corrected curve is parallel to the original but then shifted downwards so that short yields are fairly similar and deviations for longer maturities reflect differences in the extrapolation. This difference in extrapolation is likely to have a sizeable effect on liability valuation, which we examine in the next section.

\subsection{Liability valuation: a thought experiment}

In previous sections we claim that the economic effects of segmentation are rather small: they are in the ballpark of 1-3 basis points. Eventually, by use of leverage, arbitrageurs could profit from any mispricing or from small risk premium differences between different maturities. However, a more interesting aspect of the economic significance is how liability valuation of pension funds would be affected by switching from the UFR curve to our proposed term structure based on bond market data.

Our aim is to quantify the effect of different discount curves on liability valuation. To 
perform this thought experiment, we use the two curves on the lower panel of Figure 8. We assume there are two hypothetical pension funds. Both funds pay out $€ 100$ in total over a payment schedule of 60 years. Participants join a fund at the age of 25 and pay a steady stream of equal contributions over the years, until they reach retirement age at 65 . At 65 they get a steady stream of defined cash flows until they die at the age of 85 . The first fund is a large fund with a constant number of participants uniformly distributed between the age of 25 and 85 years. This implies that in each period, the fund has to pay $1 / 60$ fraction of its total liabilities, thus $€ 1.67$ out. The other fund is a young fund, in which participant are between the age of 25 and 50 years old and are in a constant supply. This means that in the first 15 years the fund does not have any payouts, but as participants gradually reach retirement age, payouts increase. They do so until the $35^{\text {th }}$ year of the schedule, when the younger fund also reaches a steady state, in which an equal number of people enter the fund at 25 and die at the age of 85 .

The upper panel of Figure 9 depicts the payout schedule of the two funds, while the lower shows the comparison between the difference in liability values discounted by either the UFR or the extrapolated NS curve. We find that the choice of the discount curve indeed matters, as the present value of liabilities is substantially smaller when the UFR approach is applied, as opposed to the market based curve. The value difference is more sizeable for the younger fund, where the duration of the liabilities is longer. The difference in the present values of liabilities is $€ 17.82$ or $28.3 \%$, while it is $€ 10.82$ and $14.5 \%$ for the steady-state fund. Moreover, switching between the UFR and Nelson-Siegel curves not only affects the difference within, but also across funds, discounting by the UFR curve enlarges the present value difference between the young and steady-state funds to $€ 18.66$, while it is $€ 11.65$ in case the market based curve is used. ${ }^{13}$

Looking at the actual size of the difference and the volatility of the present value, we

\footnotetext{
${ }^{13}$ Although, this analysis is incomplete without considering the asset side of a pension portfolio and the funding ratio, we refrain from further investigating the asset side given the large number of assumptions required to quantify these effects. Even by means of such simple analysis we can conclude that the choice of the discount rate matters, as we find that by switching from one curve to another, the present values of liabilities are different.
} 
think the differential effect of the two curves on liability valuation is large. Consequently, the impact on the funding ratio of a typical pension fund can be substantial, potentially similar in magnitude to those stemming from the annual fluctuations of funding ratios due to market returns and interest rate changes. Note, however, that the presented difference is likely conservative as it relies on the UFR curve net of the swap premium, therefore the actual difference is likely to be more significant than presented here. By deducting the swap premium, we eliminated a potential distortion that might affect the overall UFR curve, without respect of maturity segments. Nevertheless, this thought experiment already points to a direct implication on asset and liability management: all else equal, larger liability value decreases the funding ratio. This smaller value on one side of the balance sheet would have to be compensated with larger asset value and/or potentially stricter risk management.

\subsection{Policy discussion and the scope of our contribution}

The primary aim of this paper is to explore the effects of segmentation on yield and liquidity of (a representative) European nominal term structure. In particular, we analyze whether the behavior and drivers of short and long maturity bonds yields differ and how their liquidity characteristics are driven by investor groups with different holding periods. However, in doing so, this paper also contributes to the European policy discussion on the asset and liability management of pension and insurance funds. Namely, we suggest a viable alternative to the UFR method proposed by the Solvency II Directive of the European Commission and EIOPA. The UFR method aims to specify the construction of long term discount rates, by means of extrapolating swap rates beyond the last liquid point of the term structure.

There are three distinct issues regarding the current industry practice: 1) how to fit the curve and how to extrapolate beyond the last liquid point; 2) where to set the last liquid point; and 3) based on which information should long-term discount rates be determined. 
This paper does not tackle all three of these issues. We propose a simple method to fit a smooth forward curve and to extrapolate that beyond the last liquid point. We only partially assess which extrapolation method, the bond market data based NS simple or the UFR approach, performs better in the thought experiment of the previous section. Second, we take the last liquid point suggested by EIOPA and set it to 20 years to maturity. There is an open debate on where this point should be set, while EIOPA and the Netherlands uses 20 years for the division point, in Sweden the last liquid point is set at 15 years to maturity. Then the question arises, where is the actual segmentation point along the yield curve? And finally, our results suggest that long maturity bond yields might be appropriate for the valuation of long-term liabilities - especially if the distortion in long yields due to segmentation is smaller than the risk premiums in observable swap quotes.

Nevertheless, finding that long maturity bond yields are not substantially distorted has important policy implications. Part of the policy discussion on valuation of pension and insurance liabilities for regulatory purposes is how to model long term discount rates. The current approach is based on the ultimate forward rate method, which in light of our results might seem unnecessary, if yields beyond the last liquid are not distorted. In this case one could extrapolate long term discount rates from yields observed in the bond markets. Then the question arises: is the ultimate forward rate discussion much ado about nothing? One the one hand, the answer is no, as there is a lot of money at stake: pension funds and insurers together managed $€ 17$ trillion worth of assets in 2017 , thus making sure that this wealth is properly valuated is crucial. On the other hand, the answer could be positive, as it seems that we can trust yields of long maturity bonds, since any existing effects of segmentation on yields or liquidity are rather small. 


\section{Conclusion}

This paper examines the differential pricing of short and long maturity bonds. Our aim is to study whether there is segmentation along the German yield curve and discover the channels through which this would affect the pricing of short and long maturity bonds. In summary, we find low levels of yield segmentation, our results suggest that although there are statistically significant differences in the pricing and drivers of short and long maturity bonds, the corresponding economic effects are rather small. This means that long yields are not substantially distorted by demand pressure, default or liquidity premiums.

Our empirical strategy is as follows. First, to study segmentation of long and shorter maturity bonds, we construct a pair of noise measures similar to that of Hu et al. (2013). The noise measures are liquidity proxies that are based on the pricing errors of observable yields relative to a smooth curve. We find that these measures capture different aspects of liquidity: short noise is related to the age of the bond and to market and funding liquidity; while long noise is linked to bond issue level illiquidity and the US noise measure. Nevertheless, conventional liquidity proxies do not fully explain the two noise measures suggesting that they capture an aspect of illiquidity that correlates but goes beyond those measures.

Next, to further examine the pricing of bonds, we also look at the average fitting error, called the bias. We find that the bias is persistently negative, implying that the observed yields are consistently below those implied by our pricing model. To explain why long yields are "too low", we link the bias to the Roll implied bid-ask spread, time to maturity of bonds, liquidity risk and the Ted spread, flight-to-safety flows and to the credit risk of Germany. To deepen our understanding of time-series drivers of short and long maturity bond yields, we study their exposures to proxies of demand pressure, default premiums and liquidity. The yield decomposition reveals little evidence of significant segmentation in German sovereign bond markets. Short yields are mostly driven by short noise and large scale asset purchases, while both long and short yields are strongly linked 
flight-to-safety flows and to German credit quality.

Looking at the effect of segmentation on liquidity, we study how yields of the short and long ends of the yield curve are linked to a wide range of liquidity measures. We find that short noise has a significant and robust effect on average short yield, which varies over time. As opposed to this, we find that no such effect in the average long yield, while there is a liquidity spillover from the short to the long end of the yield curve. We also consider if short and long noise are related to different market forces and find that short noise is sensitive to large scale asset purchases of the ECB, and to changes in stock market volatility and flight-to-safety flows. We conclude that although these findings are in line with the theory of liquidity segmentation Amihud and Mendelson (1986); Beber et al. (2012), the economic effects of segmentation on liquidity are rather small. Nevertheless, we show that the nature of liquidity varies along the curve: liquidity of short maturity bonds seems more systematic in nature, whilst liquidity of long maturity bonds behaves independently from other market variables.

Finding that long maturity bond yields are not substantially distorted has important policy implications. Part of the policy discussion on valuation of pension and insurance liabilities for regulatory purposes is how to model long term discount rates. In light of our results the current regulatory practice and the use of the UFR method seems unnecessary if yields beyond the last liquid are not distorted. In this case, one could extrapolate long term discount rates from yields observed in bonds markets. Then the question arises: is the ultimate forward rate discussion much ado about nothing? One the one hand, the answer is no, as there is a lot of money at stake: pension funds and insurers together managed $€ 17$ trillion worth of assets in 2017 , thus making sure that this wealth is properly valuated is crucial. On the other hand, the answer is yes: it seems that we can trust yields of long maturity bonds as any existing effects of segmentation on yields or liquidity are rather small. 


\section{References}

Amihud, Y. and Mendelson, H. (1986). Asset Pricing and the Bid-Ask Spread. Journal of Financial Economics, 17 (2): 223-249.

Ashcraft, A., Gârleanu, N., and Pedersen, L. H. (2010). Two Monetary Tools: Interest Rates and Haircuts. Working paper, New York University.

Baele, L., Bekaert, G., Inghelbrecht, K., and Wei, M. (2015). Flights-to-Safety. Working paper 230, National Bank of Belgium.

Bai, J., Julliard, C., and Yuan, K. (2012). Eurozone Sovereign Bond Crisis: Liquidity or Fundamental Contagion? Working paper, Federal Reserve Bank of New York.

Beber, A., Brandt, M. W., and Kavajecz, K. A. (2009). Flight-to-Quality or Flight-to-Liquidity? Evidence from the Euro-Area Bond Market. Review of Financial Studies, 22 (3): 925-957.

Beber, A., Driessen, J., and Tuijp, P. (2012). Pricing Liquidity Risk with Heterogeneous Investment Horizons. Working paper.

Bliss, R. R. and Fama, E. F. (1987). The Information in Long-Maturity Forward Rates. American Economic Review, 77 (4): 680-692.

Brunnermeier, M. and Pedersen, L. H. (2009). Market Liquidity and Funding Liquidity. Review of Financial Studies, 22 (6): 2201-2238.

Bühler, W. and Vonhoff, V. (2011). Term Structures of Liquidity Premia in the U.S. Treasury Market. Working paper.

Christensen, J. H. E. and Gillan, J. M. (2013). Does Quantitative Easing Affect Market Liquidity? Working paper 2013-26, Federal Reserve Bank of San Francisco.

Christensen, J. H. E., Lopez, J. A., and Mussche, P. L. (2018). Extrapolating long-maturity bond yields for financial risk measurement. Working Paper 2018-09, Federal Reserve Bank of San Francisco.

Cochrane, J. H. and Piazzesi, M. (2005). Bond Risk Premia. American Economic Review, 95 (1): 138-160.

D'Amico, S., English, W., Lopez-Salido, D., and Nelson, E. (2012). The Federal Reserve's Large-Scale Asset Purchase Programs: Rationale and Effects. Finance and Economics Discussion Series, Working paper 2012-85, Federal Reserve Board.

D'Amico, S. and King, T. B. (2013). The Flow and Stock Effects of Large-Scale Treasury Purchases: Evidence on the Importance of Local Supply. Journal of Financial Economics, 108 (2): 275-564.

Darbha, M. and Dufour, A. (2014). The Term Structure of Bond Market Illiquidity and Default Risk. Working paper.

De Pooter, M. (2007). Examining the Nelson-Siegel Class of Term Structure Models. Discussion paper 07-043/4, Tinbergen Institute. 
De Pooter, M., Martin, R. F., and Pruitt, S. (2013). The Liquidity Effects of Official Bond Market Intervention. Working paper.

De Santis, R. A. (2015). A Measure of Redenomination Risk. Working Paper 1785, ECB.

Dick-Nielsen, J., Feldhütter, P., and Lando, D. (2012). Corporate Bond Liquidity Before and After the Onset of the Subprime Crisis. Journal of Financial Economics, 103 (3): 471-492.

Diebold, F. X. and Li, C. (2006). Forecasting the Term Structure of Government Bond Yields. Journal of Econometrics, 130 (2): 337-364.

Duffie, D. (2010). Asset Price Dynamics with Slow-Moving Capital. Journal of Finance, 65 (4): $1238-1268$.

Eidam, F. (2017). Gap-Filling Government Debt Maturity Choice. Working paper.

Ejsing, J., Grothe, M., and Grothe, O. (2012). Liquidity and Credit Risk Premia in Government Bond Yields. Working paper 1440, ECB.

Ericsson, J. and Renault, O. (2006). Liquidity and Credit Risk. Journal of Finance, 61 (5): 2219-2250.

Eser, F. and Schwaab, B. (2016). Evaluating the Impact of Unconventional Monetary Policy Measures: Empirical Evidence from the ECB's Securities Markets Programme. Journal of Financial Economics, 119 (1): 147-167.

Fontaine, J.-S. and Garcia, R. (2012). Bond Liquidity Premia. Review of Financial Studies, 25 (4): 1207-1254.

Gehde-Trapp, M., Schuster, P., and Uhrig-Homburg, M. (2018). The Term Structure of Bond Liquidity. Journal of Financial and Quantitative Analysis, forthcoming.

Gorton, G. B. and Metrick, A. (2010). Haircuts. Federal Reserve Bank of St. Louis Review, 507-520.

Goyenko, R., Subrahmanyam, A., and Uhkov, A. (2011). The Term Structure of Bond Market Liquidity and Its Implications for Expected Bond Returns. Journal of Financial and Quantitative Analysis, 46 (1): 111-139.

Greenwood, R., Hanson, S. G., and Stein, J. C. (2015). A Comparative-Advantage Approach to Government Debt Maturity. Journal of Finance, 70 (4): 1683-1722.

Greenwood, R. and Vayanos, D. (2010). Price Pressure in the Government Bond Market. American Economic Review, 100 (2): 585-90.

Greenwood, R. and Vayanos, D. (2014). Bond Supply and Excess Bond Returns. Review of Financial Studies, 27 (3): 663-713.

Greenwood, R. and Vissing-Jorgensen, A. (2018). The Impact of Pensions and Insurance on Global Yield Curves. Working paper.

Gromb, D. and Vayanos, D. (2002). Equilibrium and Welfare in Markets with Financially Constrained Arbitrageurs. Journal of Financial Economics, 66 (2): 361-407. 
Guibaud, S., Nosbusch, Y., and Vayanos, D. (2013). Bond Market Clienteles, the Yield Curve and the Optimal Maturity Structure of Government Debt. Review of Financial Studies, 26 (8): 1914-1961.

Gürkaynak, R. S., Sack, B., and Wright, J. H. (2007). The U.S. Treasury Yield Curve: 1961 to the Present. Journal of Monetary Economics, 54 (8): 2291-2304.

Hu, X., Pan, J., and Wang, J. (2013). Noise as Information for Illiquidity. Journal of Finance, 68 (6): 2223-2772.

Insurance Europe (2018). European insurance in figures: 2016 data. /urlhttps://www.insuranceeurope.eu/european-insurance-figures-2016-data.

Investment and Pensions Europe (2017). Top 1000: A bird's eye view of $\$ 7$ trn. https://www.ipe.com/reports/special-reports/top-1000-pension-funds/ top-1000-a-birds-eye-view-of-7trn/10020502.fullarticle.

Kempf, A., Korn, O., and Uhrig-Homburg, M. (2012). The Term Structure of Illiquidity Premiums. Journal of Banking 85 Finance, 36 (5): 1381-1391.

Klinger, S. and Lando, D. (2018). Safe-Haven CDS Premiums. Review of Financial Studies, 31 (5): 1856-1895.

Krishnamurthy, A. (2002). The Bond/Old Bond Spread. Journal of Financial Economics, 66 (2): 463-506.

Krishnamurthy, A., Nagel, S., and Vissing-Jorgensen, A. (2018). ECB Policies Involving Government Bond Purchases: Impact and Channels. Review of Finance, 22 (1): 1-44.

Krishnamurthy, A. and Vissing-Jorgensen, A. (2011). The Effects of Quantitative Easing on Interest Rates: Channels and Implications for Policy. resreport 17555, Brookings Papers on Economic Activity.

Liu, J., Longstaff, F. A., and Mandell, R. E. (2006). The Market Price of Risk in Interest Rate Swaps: The Roles of Default and Liquidity Risks. The Journal of Business, 79 (5): 2337-2360.

Longstaff, F. A. (2004). The Flight to Liquidity Premium in U.S. Treasury Bond Prices. Journal of Business, 77 (3): 511-526.

Mitchell, M., Pedersen, L. H., and Pulvino, T. (2007). Slow Moving Capital. American Economic Review PEP , 97 (2): 215-220.

Monfort, A. and Renne, J.-P. (2014). Decomposing Euro-Area Sovereign Spreads: Credit and Liquidity Risks. Review of Finance, 18 (6): 2103-2151.

Næs, R., Skjeltorp, J. A., and Ødegaard, B. A. (2011). Stock Market Liquidity and the Business Cycle. The Journal of Finance, 66 (1): 139-176.

Pelizzon, L., Subrahmanyam, M., Tomio, D., and Uno, J. (2016). Sovereign Credit Risk, Liquidity, and ECB Intervention. Journal of Financial Economics, 122 (1): 86 - 115.

Pelizzon, L., Subrahmanyam, M., Uno, J., and Tomio, D. (2014). The Microstructure of the European Sovereign Bond Market. Working paper, New York University. 
Pflueger, C. E. and Viceira, L. M. (2011). Inflation-Indexed Bonds and the Expectations Hypothesis. Annual Review of Financial Economics, 3 (1): 139-158.

Pflueger, C. E. and Viceira, L. M. (2015). Return Predictability in the Treasury Market: Real Rates, Inflation, and Liquidity. In Veronesi, P., editor, Handbook of Fixed-Income Securities. Wiley and Sons, New Jersey, New Jersey.

Phillips, A. L. (2003). In the Long End of the Spectrum. Journal of Academy of Business and Economics, 1 (1).

Quaedvlieg, R. and Schotman, P. C. (2016). Score-Driven Nelson Siegel: Hedging Long-Term Liabilities. Technical report.

Schuster, P. and Uhrig-Homburg, M. (2013). The Term Structure of Bond Market Liquidity Conditional on the Economic Environment: An Analysis of Government Guaranteed Bonds. Working paper.

Schwarz, K. (2015). Mind the Gap: Disentangling Credit and Liquidity Risks in Spreads. Working paper.

Shleifer, A. and Vishny, R. W. (1997). The Limits of Arbitrage. Journal of Finance, 52 (1): $35-55$.

Simon, Z. (2015). Not Risk Free: The Relative Pricing of Euro Area Inflation-Indexed and Nominal Bonds. Discussion paper 11/2015-074, Netspar.

Vayanos, D. and Vila, J.-L. (2009). A Preferred-Habitat Model of the Term Structure of Interest Rates. Discussion paper 7547, CEPR. 


\section{Table 1}

\section{Summary statistics of noise measures and the bias}

The table presents descriptive statistics of different noise measures and the bias. Noise measures and the bias are derived from the difference between the observable market yields and their theoretical counterparts, based on Nelson-Siegel curves fitted on German bonds. Panels A and B contain information on short and long noise measures, respectively. Noise is the root mean squared pricing error of yields. Panel C present the noise measure of Hu et al. (2013) (HPW), which is based on US Treasuries, obtained from the website of Jun Pan. Panel D presents the bias, the mean pricing error of long maturity bond yields. All measures are in basis points.

\begin{tabular}{|c|c|c|c|c|c|}
\hline \multicolumn{6}{|c|}{ Panel A. Short noise } \\
\hline & \# of bonds & Mean & St.dev & Min & $\operatorname{Max}$ \\
\hline $2000-2015$ & $38-56$ & 6.4168 & 2.7791 & 2.0036 & 23.8380 \\
\hline 2005-2015 & $38-55$ & 7.9122 & 7.8396 & 2.3838 & 20.4675 \\
\hline \multicolumn{6}{|c|}{ Panel B. Long noise } \\
\hline & \# of bonds & Mean & St.dev & Min & $\operatorname{Max}$ \\
\hline $2000-2015$ & $1-8$ & 18.8233 & 10.7720 & 1.7053 & 50.3190 \\
\hline $2005-2015$ & $1-8$ & 19.3881 & 10.4078 & 1.7053 & 49.5880 \\
\hline \multicolumn{6}{|c|}{ Panel C. US noise measure from HPW (2013) } \\
\hline & \# of bonds & Mean & St.dev & Min & Max \\
\hline 2000-Dec 2014 & appr. 165 & 3.1009 & 2.6507 & 0.7232 & 20.4675 \\
\hline 2005-Dec 2014 & appr. 165 & 3.0891 & 3.1842 & 0.7232 & 20.4675 \\
\hline \multicolumn{6}{|l|}{ Panel D. Bias } \\
\hline & \# of bonds & Mean & St.dev & Min & Max \\
\hline 2000-2015 & $1-8$ & -1.5346 & 19.9604 & -47.9043 & 50.2931 \\
\hline $2005-2015$ & $1-8$ & -9.2537 & 17.4175 & -47.9043 & 25.7488 \\
\hline
\end{tabular}




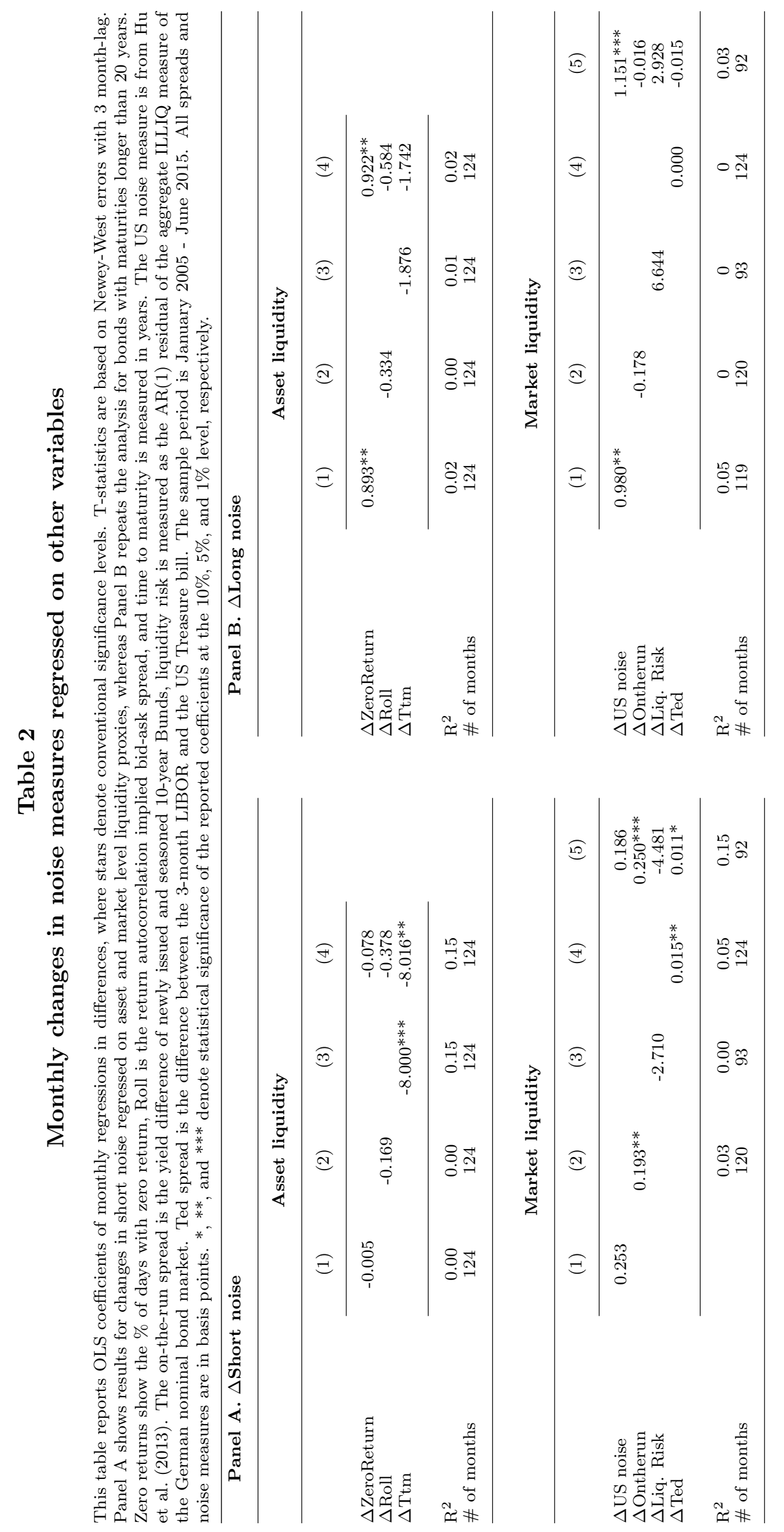


Table 3

Drivers of the bias - structural distortions in the curve

This table presents OLS coefficients of monthly regressions in differences, where stars denote conventional significance levels. T-statistics are based on Newey-West errors of 3 month lags. Panel A shows results of univariate regressions of the bias on liquidity, demand pressure, default risk and volatility proxies, whereas Panel B repeats the analysis in a multivariate setting. Variable description of liquidity proxies can be found of Table 2. Flight-to-safety is the first PCA of CDS spreads of distressed Eurozone countries, and ECB asset growth is the change in the logarithm of the asset side of the ECB balance sheet. KfW spread is the yield difference between 10-year KFW agency bond and a maturity-matched German Bund, and VIX is the volatility index issued by CBOE. The sample period is January 2005 - June 2015 . All spreads and noise measures are in basis points. $* * *$, and $* * *$ denote statistical significance of the reported coefficients at the $10 \%, 5 \%$, and $1 \%$ level, respectively.

\begin{tabular}{|c|c|c|c|}
\hline \multicolumn{4}{|c|}{ Panel A: Univariate regressions } \\
\hline \multicolumn{4}{|c|}{ Asset liquidity } \\
\hline & $(1)$ & $(2)$ & $(3)$ \\
\hline $\begin{array}{l}\Delta \text { ZeroReturn } \\
\Delta \text { Roll } \\
\Delta \text { Ttm }\end{array}$ & -0.278 & $-2.560^{*}$ & $-3.131^{*}$ \\
\hline $\begin{array}{l}\mathrm{R}^{2} \\
\# \text { of months }\end{array}$ & $\begin{array}{c}0 \\
124\end{array}$ & $\begin{array}{c}0.04 \\
124\end{array}$ & $\begin{array}{c}0.03 \\
124\end{array}$ \\
\hline
\end{tabular}

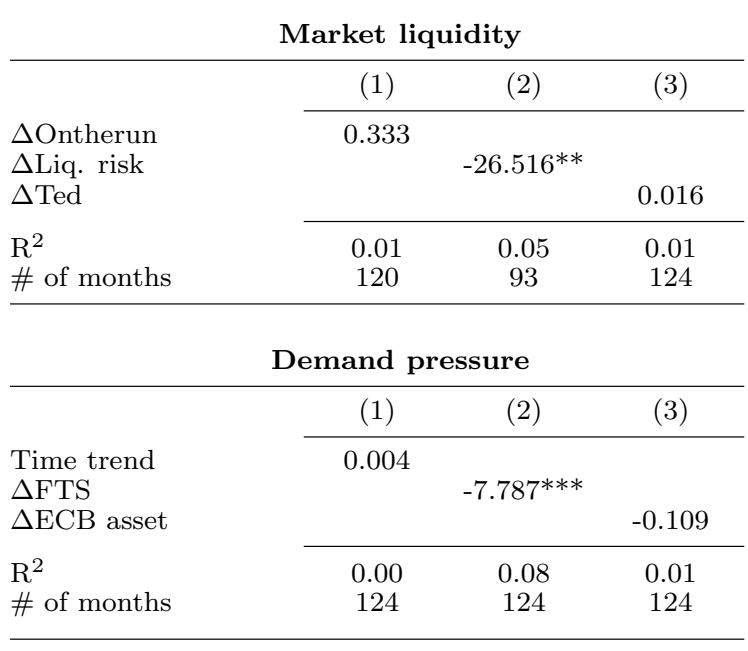

\section{$\Delta$ ZeroReturn \\ $\Delta$ Roll \\ $\Delta \mathrm{Ttm}$ \\ $\Delta$ US noise \\ $\Delta$ Ontherun}

$\Delta$ Liq. risk

$\Delta$ Ted

Time trend

$\triangle \mathrm{FTS}$

$\triangle \mathrm{ECB}$ asset

$\triangle \mathrm{CDS}$

$\triangle \mathrm{KfW}$

$\Delta$ VIX

$\mathrm{R}^{2}$

\# of months
Panel B: Multivariate regressions

\begin{tabular}{ccc}
$(1)$ & $(2)$ & $(3)$ \\
\hline 0.409 & & 0.090 \\
$-3.749^{* *}$ & & $-3.686^{* *}$ \\
-2.374 & & -1.875 \\
& & -0.498 \\
$-1.283^{* * *}$ & & 0.401 \\
0.291 & & -13.117 \\
-17.381 & & $0.035^{*}$ \\
0.022 & & -0.006 \\
& -0.007 & -2.352 \\
& -2.602 & -0.117 \\
& 0.017 & -0.142 \\
& $-0.176^{* *}$ & 0.029 \\
& 0.050 & -0.091 \\
\hline 0.20 & -0.082 & 0.31 \\
92 & 101 & 92 \\
\hline
\end{tabular}

Default and volatility

\begin{tabular}{lccc}
\hline & $(1)$ & $(2)$ & $(3)$ \\
\cline { 2 - 4 }$\Delta$ CDS & $-0.224^{* * *}$ & & \\
$\Delta$ KfW & & -0.056 & \\
$\Delta$ VIX & & & $-0.163^{*}$ \\
\cline { 2 - 4 } $\mathrm{R}^{2}$ & 0.12 & 0.01 & 0.02 \\
$\#$ of months & 124 & 101 & 124 \\
\hline
\end{tabular}


Table 4

Yield decomposition - the effect of segmentation

This table reports results of monthly OLS regressions of yield differences. Variables with delta are differences, whereas time trend and the ECB asset growth are in levels. Short noise is the squared mean pricing error of these bonds relative to the smooth Nelson-Siegel curve. Description of variables can be found in Tables 2 and 3 . Crisis dummy is defined to be 1 for the period after September 2008, whereas No crisis dummy equals 1 before that date. The sample period is January 2005 - June 2015. All spreads and noise measures are in basis points. The absolute value of Newey-West 3 month-lagged t-statistics are in parentheses, while $* * *$, and $* * *$ denote significance at the $10 \%, 5 \%$, and $1 \%$ level.

Panel A. Decomposition of short yields

$\Delta$ Short noise

Time trend

ECB asset growth

$\Delta$ Flight-to-safety

$\triangle \mathrm{CDS}$

$\Delta \mathrm{KfW}$

$\Delta$ Long noise

Constant

Time to maturity

$\Delta \mathrm{US}$ noise

Market liquidity pr.

$\mathrm{R}^{2}$

N
(1)

(2)

\begin{tabular}{cc}
\hline-0.3214 & -0.2692 \\
$(1.59)$ & $(1.29)$ \\
-0.0111 & -0.005 \\
$(0.89)$ & $(0.21)$ \\
-0.2807 & -0.1472 \\
$(2.84)^{* * *}$ & $(1.23)$ \\
-9.0968 & -11.2594 \\
$(2.88)^{* * *}$ & $(3.41)^{* * *}$ \\
0.1325 & 0.1779 \\
$(1.91)^{*}$ & $(2.40)^{* *}$ \\
-0.1787 & -0.1583 \\
$(2.89)^{* * *}$ & $(2.40)^{* *}$ \\
0.0713 & 0.0522 \\
$(0.79)$ & $(0.58)$ \\
7.0829 & 5.2419 \\
$(0.92)$ & $(0.55)$ \\
\hline No & Yes \\
No & Yes \\
No & Yes \\
\hline 0.31 & 0.46 \\
101 & 92 \\
\hline
\end{tabular}

Panel B. Decomposition of long yields

\begin{tabular}{|c|c|c|}
\hline & (1) & $(2)$ \\
\hline$\Delta$ Long noise & $\begin{array}{c}0.2211 \\
(1.73)^{*}\end{array}$ & $\begin{array}{c}0.2333 \\
(1.72)^{*}\end{array}$ \\
\hline Time trend & $\begin{array}{c}-0.0162 \\
(0.90)\end{array}$ & $\begin{array}{c}-0.0255 \\
(0.72)\end{array}$ \\
\hline ECB asset growth & $\begin{array}{c}0.0752 \\
(0.54)\end{array}$ & $\begin{array}{c}-0.0755 \\
(0.42)\end{array}$ \\
\hline$\Delta$ Flight-to-safety & $\begin{array}{l}-8.8555 \\
(1.99)^{* *}\end{array}$ & $\begin{array}{l}-8.4888 \\
(1.71)^{*}\end{array}$ \\
\hline$\Delta \mathrm{CDS}$ & $\begin{array}{c}0.2538 \\
(2.60)^{* *}\end{array}$ & $\begin{array}{c}0.2412 \\
(2.14)^{* *}\end{array}$ \\
\hline$\Delta \mathrm{KfW}$ & $\begin{array}{l}-0.2181 \\
(2.50)^{* *}\end{array}$ & $\begin{array}{c}-0.2752 \\
(2.73) * * *\end{array}$ \\
\hline$\Delta$ Short noise & $\begin{array}{c}0.3815 \\
(1.34)\end{array}$ & $\begin{array}{c}0.4264 \\
(1.36)\end{array}$ \\
\hline Constant & $\begin{array}{c}9.8386 \\
(0.91)\end{array}$ & $\begin{array}{c}21.3583 \\
(1.42)\end{array}$ \\
\hline Time to maturity & No & Yes \\
\hline$\Delta \mathrm{US}$ noise & No & Yes \\
\hline Market liquidity pr. & No & Yes \\
\hline $\mathrm{R}^{2}$ & 0.17 & 0.24 \\
\hline $\mathrm{N}$ & 101 & 92 \\
\hline
\end{tabular}




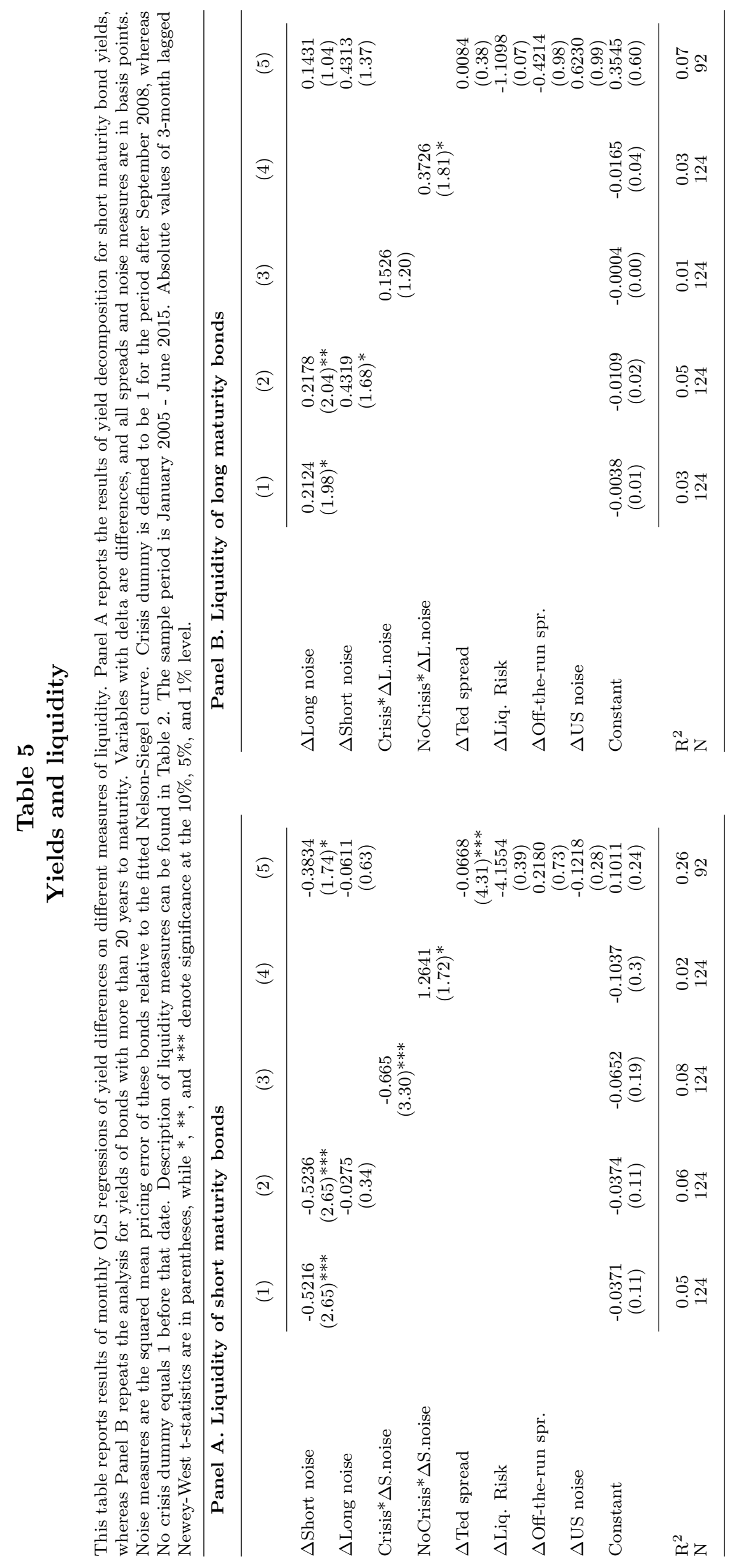




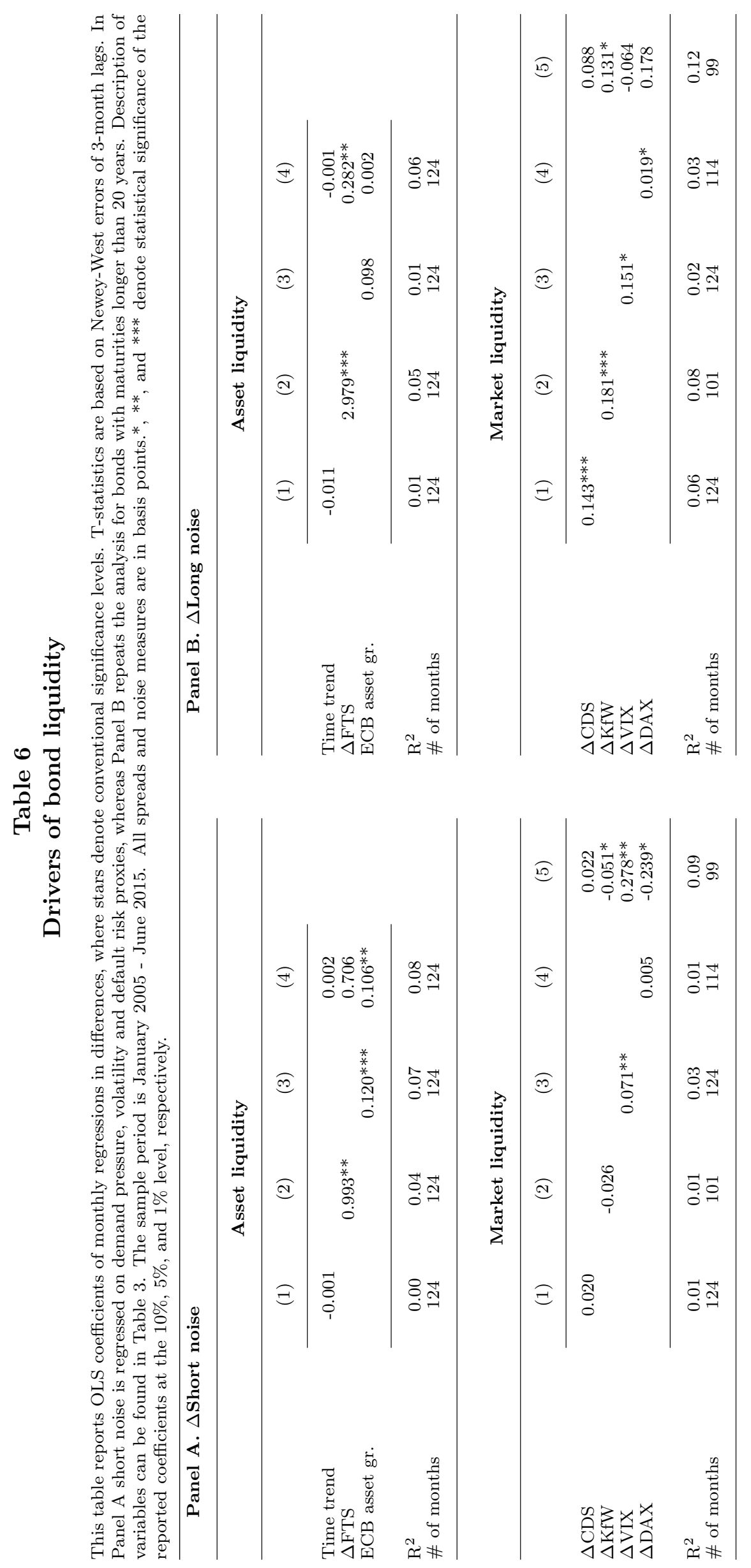



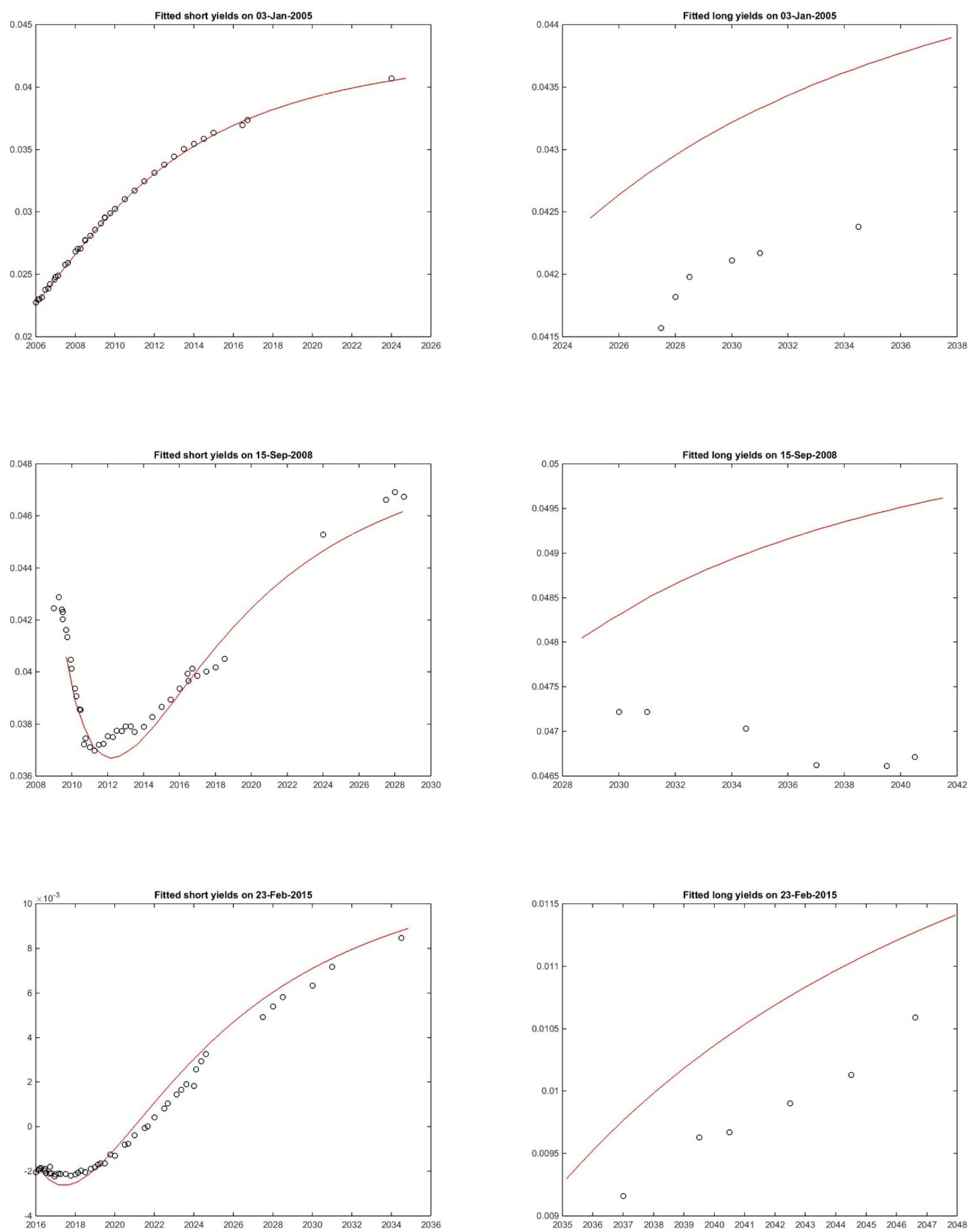

\section{Figure 1 Fitted par-coupon yield curves and observable short and long yields}

The figures depict the fitted par-coupon curves and the observable yields for three days in the sample: January 3, 2005, September 152008 and February 23 2015. The left panels show the short end of the yield curve with bonds of less than 20 years to maturity, whilst the right panel shows maturities longer than 20 years. For these bonds noise is based on the extrapolated curve. 


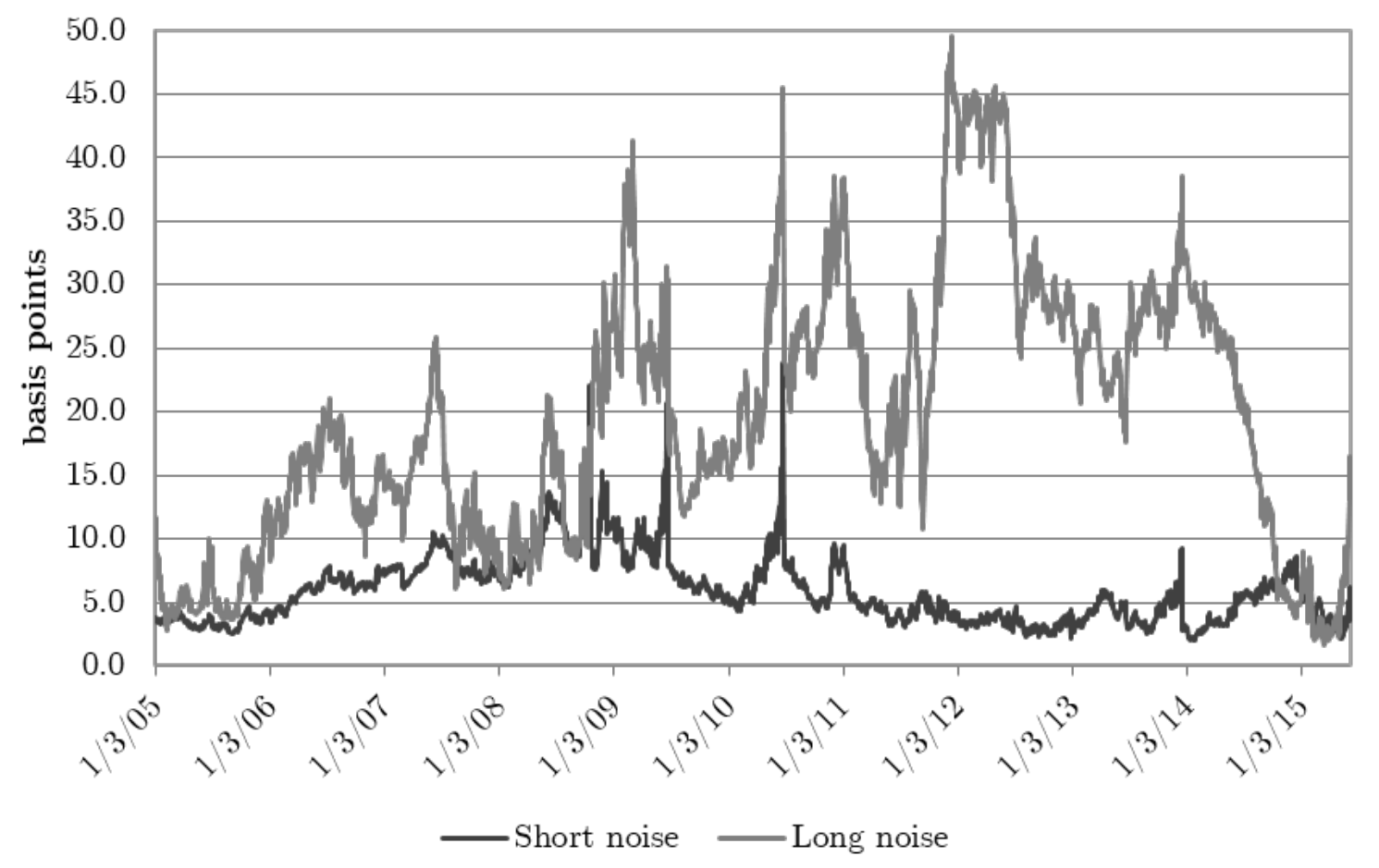

Figure 2 Daily time-series of noise measures in basis points

The figure plots the daily time series of the noise measures for the long and short ends of the yield curve, where long bonds are those of maturities longer than 20 years. Noise is the root mean squared deviation from the smooth Nelson-Siegel curve fitted on German sovereign notes and bonds with maturities between 6 months and 20 years. For bonds with longer maturities, noise is based on the extrapolation of this smooth curve. 


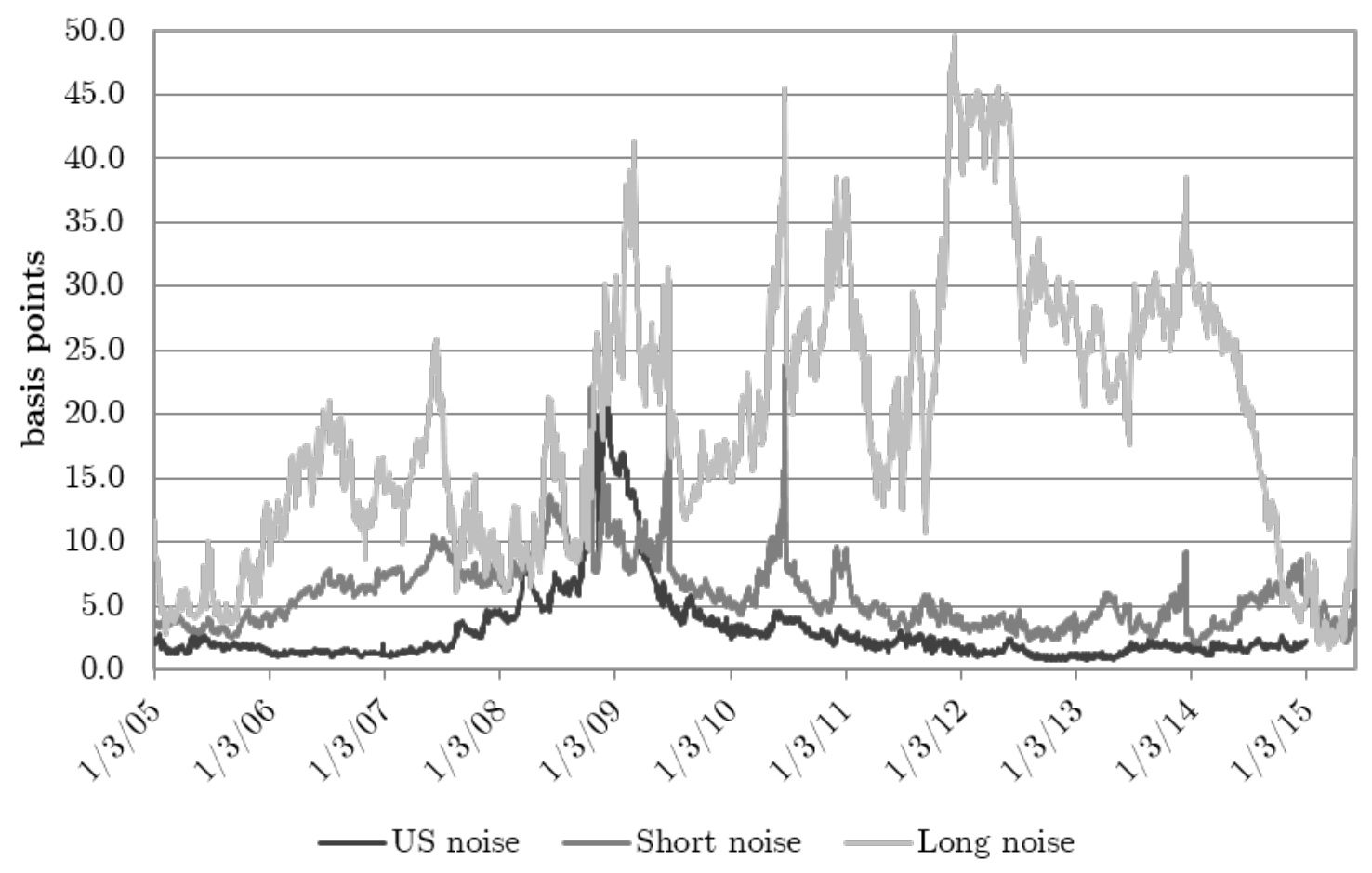

Figure 3 Comparison of German and US noise measures

The figure compares the time-series of noise measures of the short and long ends of the German yield curves to the noise measure fitted on US Treasuries by Hu et al. (2013). 

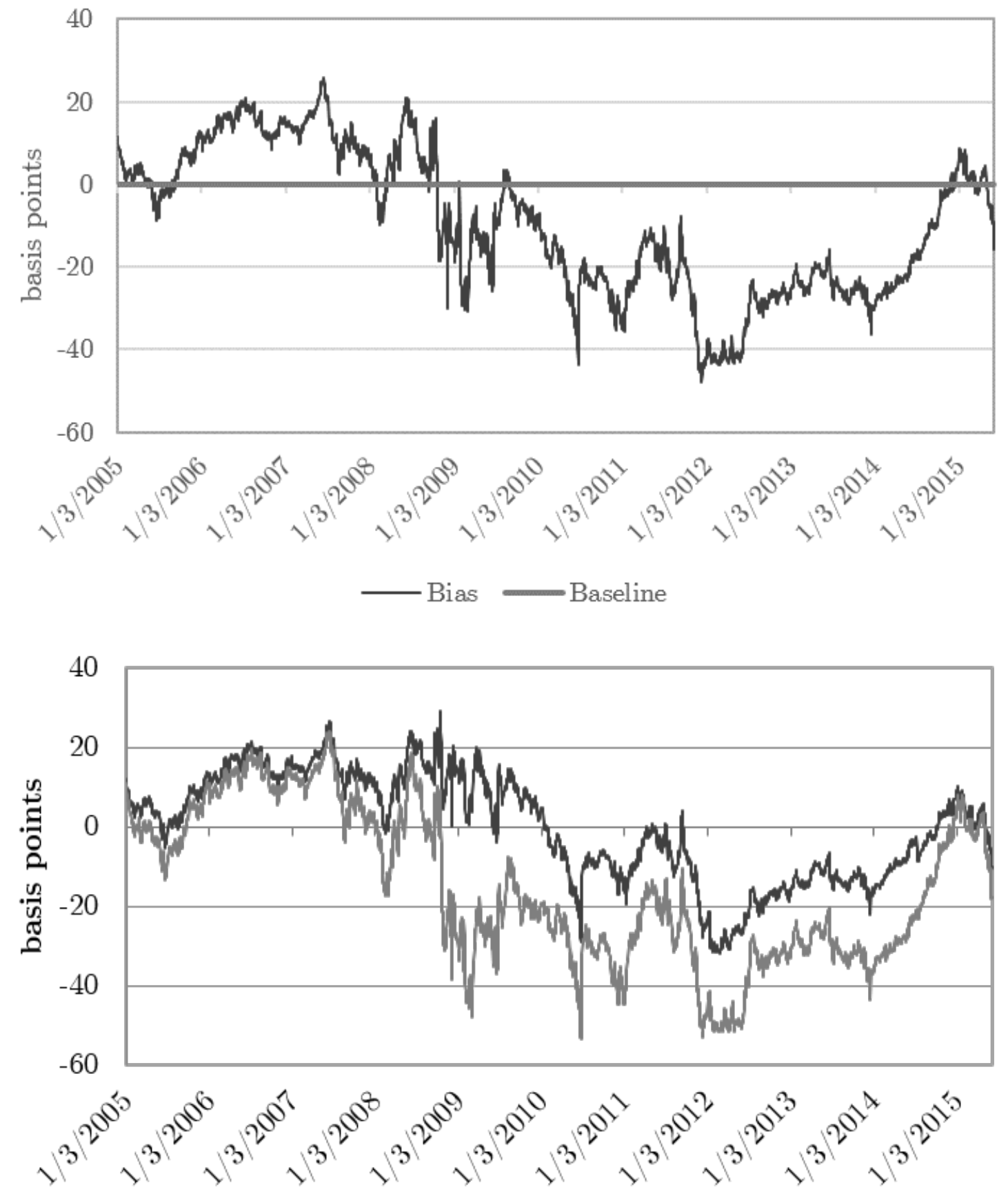

Bias 20-25 yrs

Bias 25+ yrs

Figure 4 Daily time series of the bias

The upper panel of the figure plots the daily time series of the bias. The bias is the structural deviation of long maturity bonds, measured as the fitting error of long maturity bonds relative to the smooth Nelson-Siegel curve, which is fitted on German sovereign notes and bonds with maturities between 6 months and 20 years. The lower panel plots these fitting errors for two maturity buckets: $20-25$ and $25+$ years to maturity. 


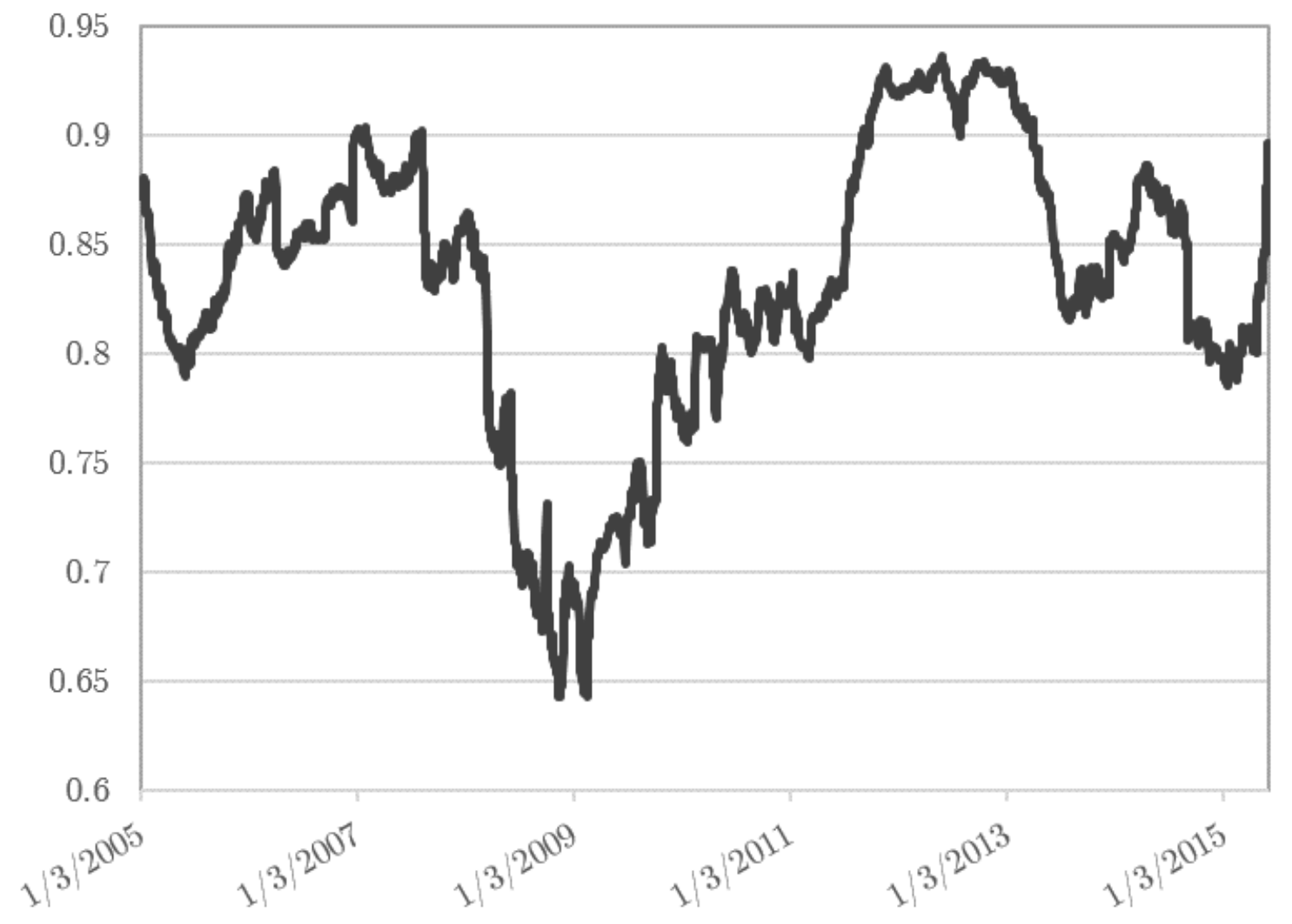

Figure 5 Correlation between the change in short and long yields

The figure plots the correlation between first differences of short and long maturity bonds yields, estimated with a 180-day rolling window. 


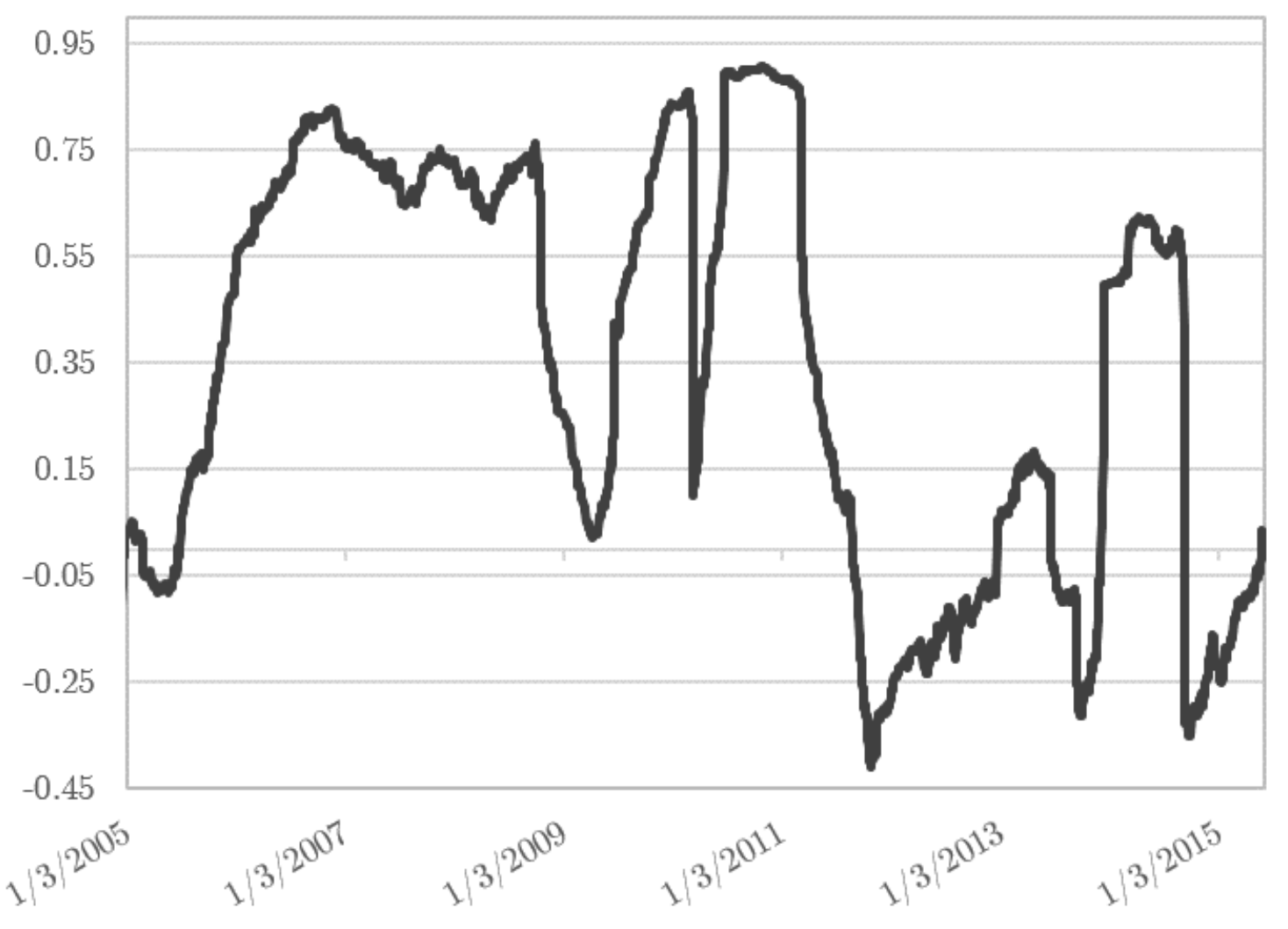

Figure 6 Correlation between the change of short and long noise

The figure plots the correlation between the first differences in noise measures of short and long maturity bonds, estimated with a 180-day rolling window. 


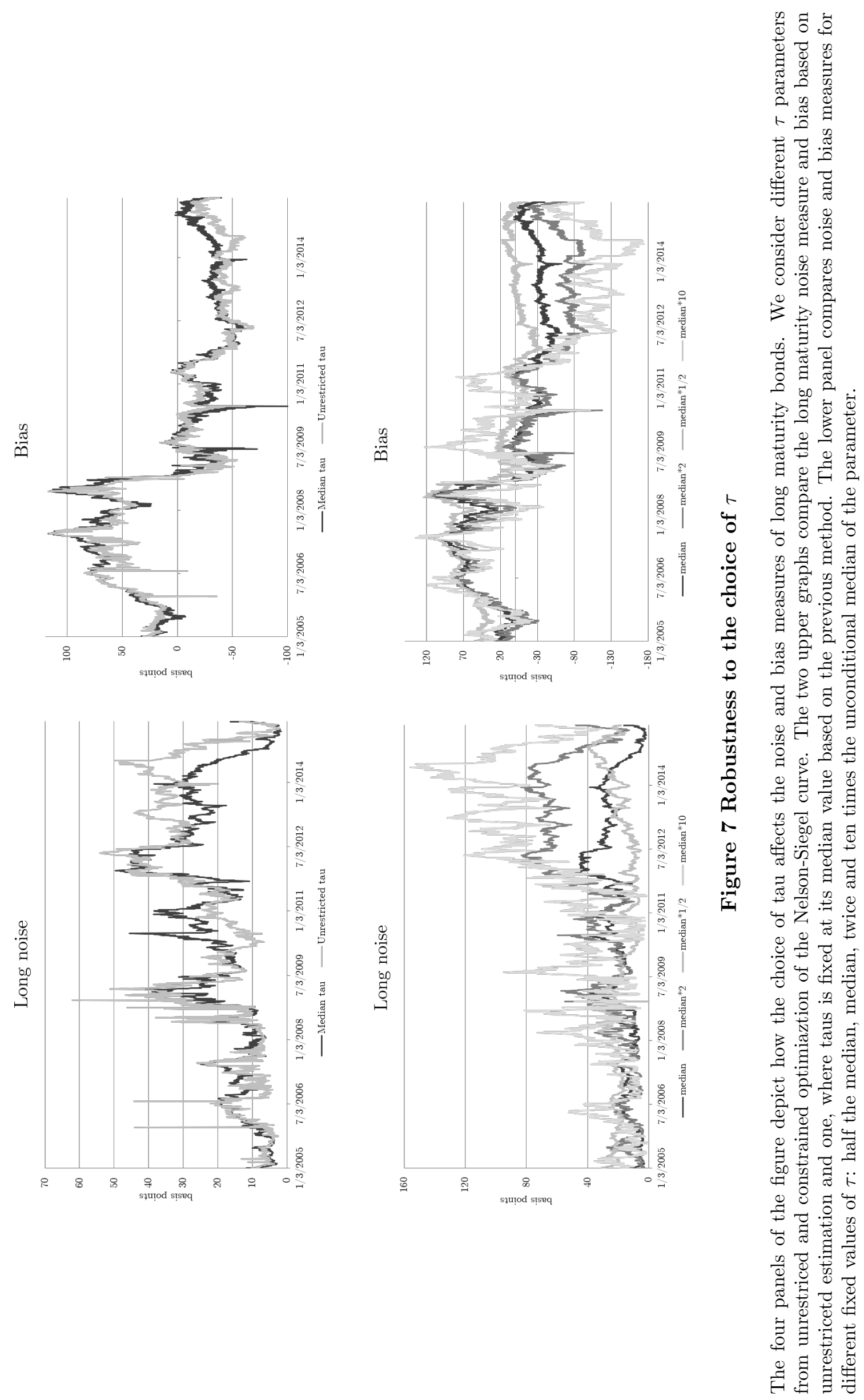




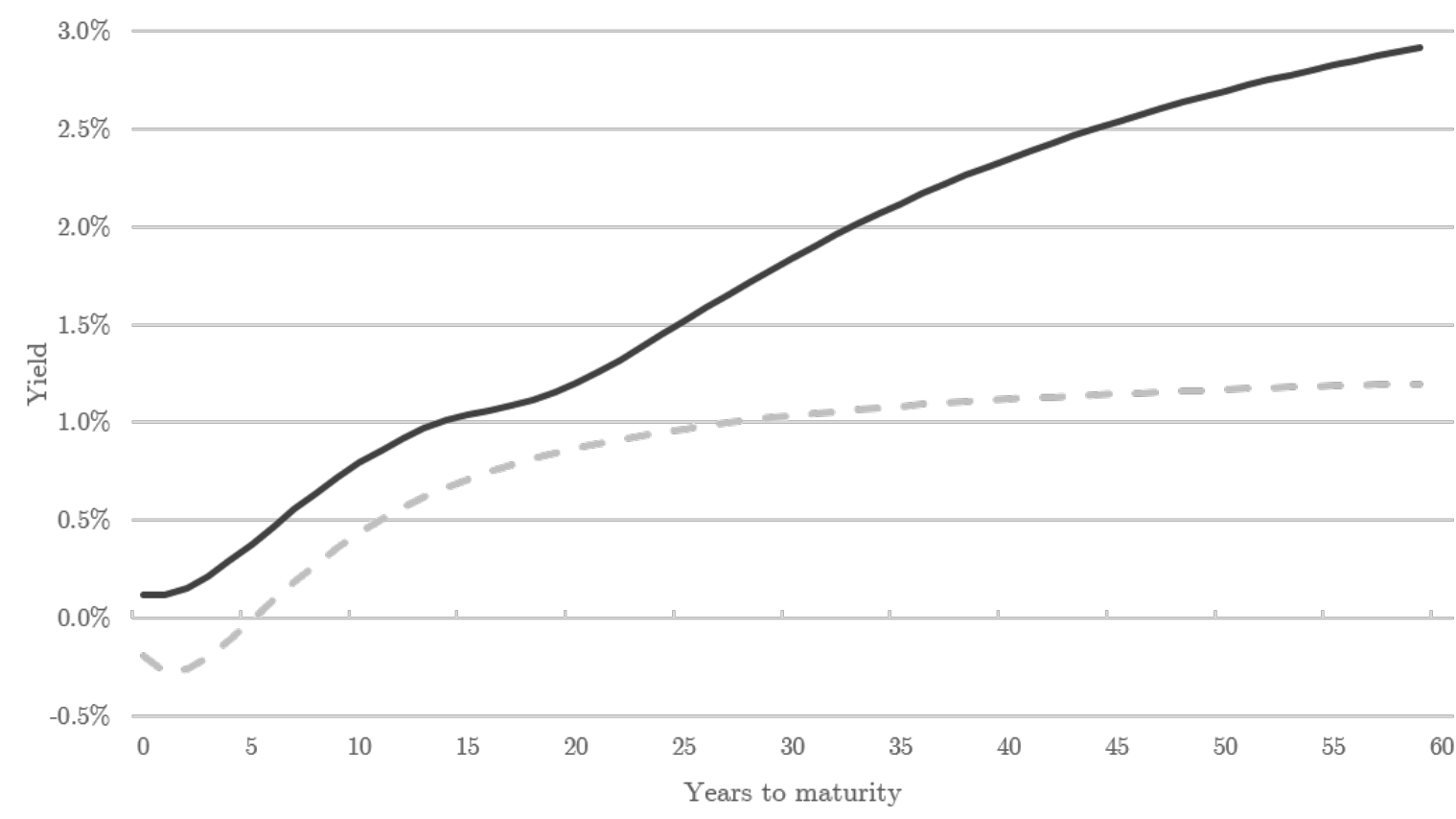

$\longrightarrow$ UFR shifted $\quad-$ NS extrapolated

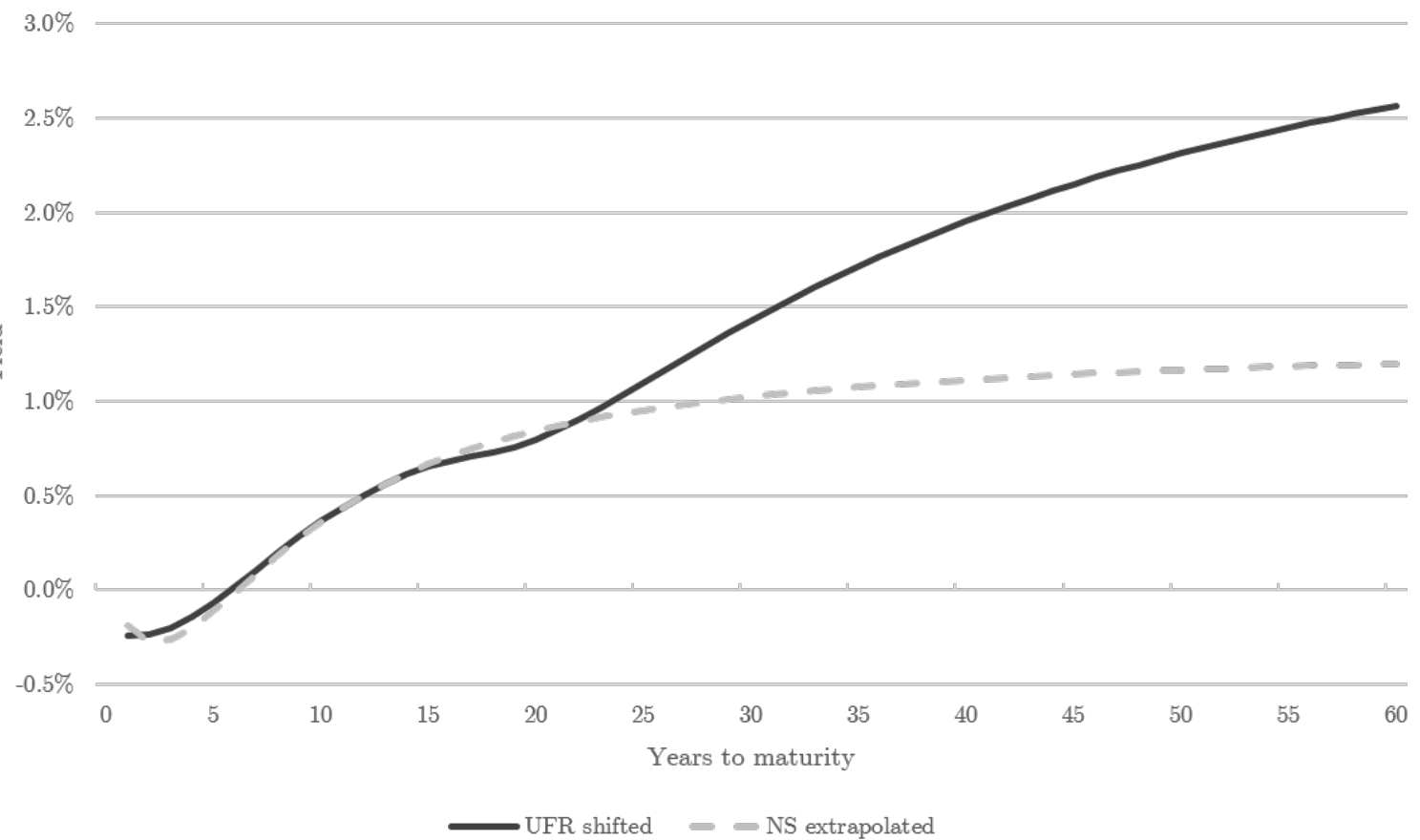

Figure 8 Regulatory vs. Nelson Siegel curves

The figures above depict the yield curve on February 23, 2015. Both panels compare the UFR curve, fitted on in interest swap data, to the Nelson Siegel curve of the study extrapolated beyond 20 years to maturity. The panel above depicts the UFR curve as it has been provided by the Dutch Central Bank (DNB, while the panel below shows the unchanged Nelson Siegel curve together with the UFR curve net of the swap premium. The swap premium likely reflects the sum of compensation for counterparty risk in bilateral swap transactions and illiquidity of certain contracts. 
Cash flow schedule

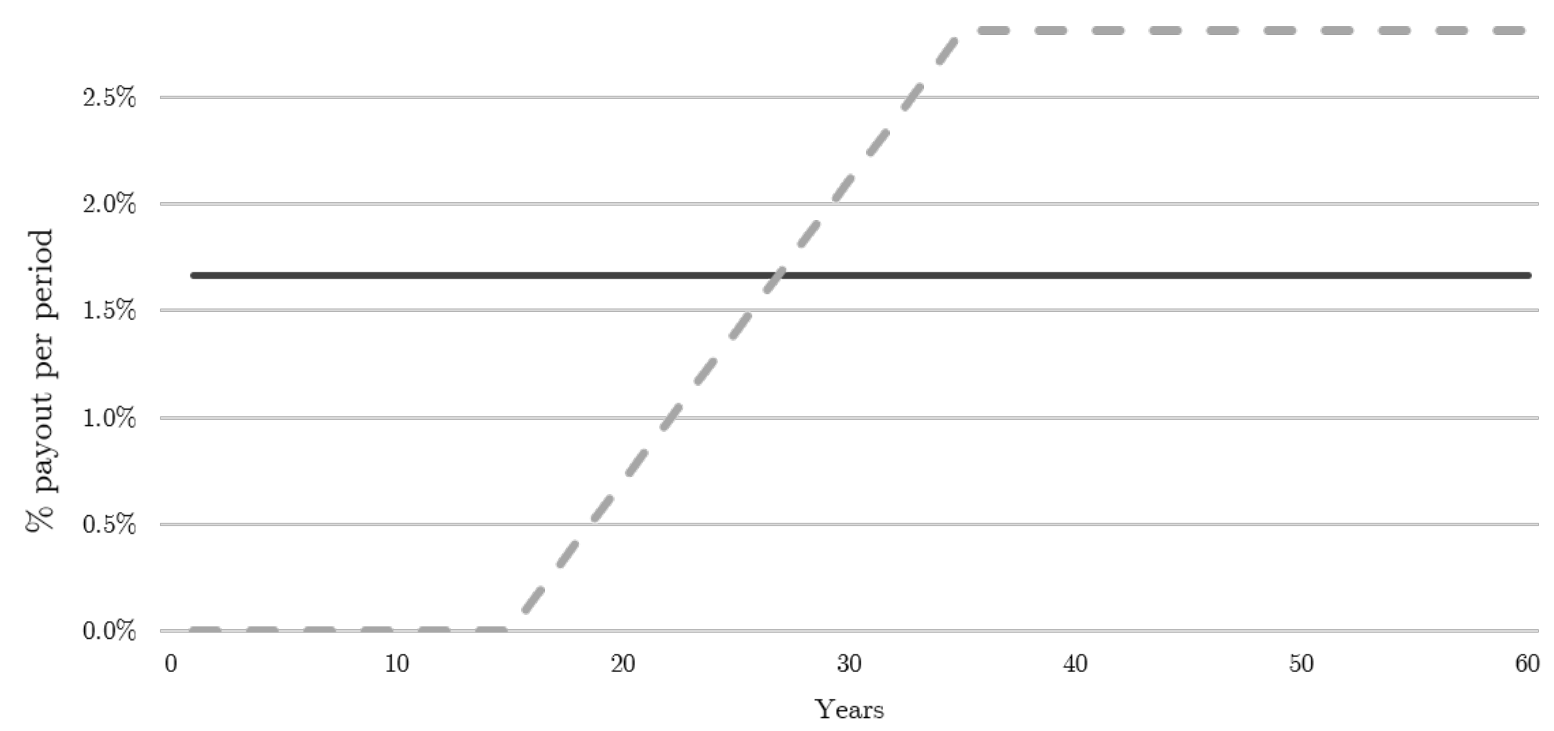

— steady state fund - - -young_fund

\section{Present value of liabilities}

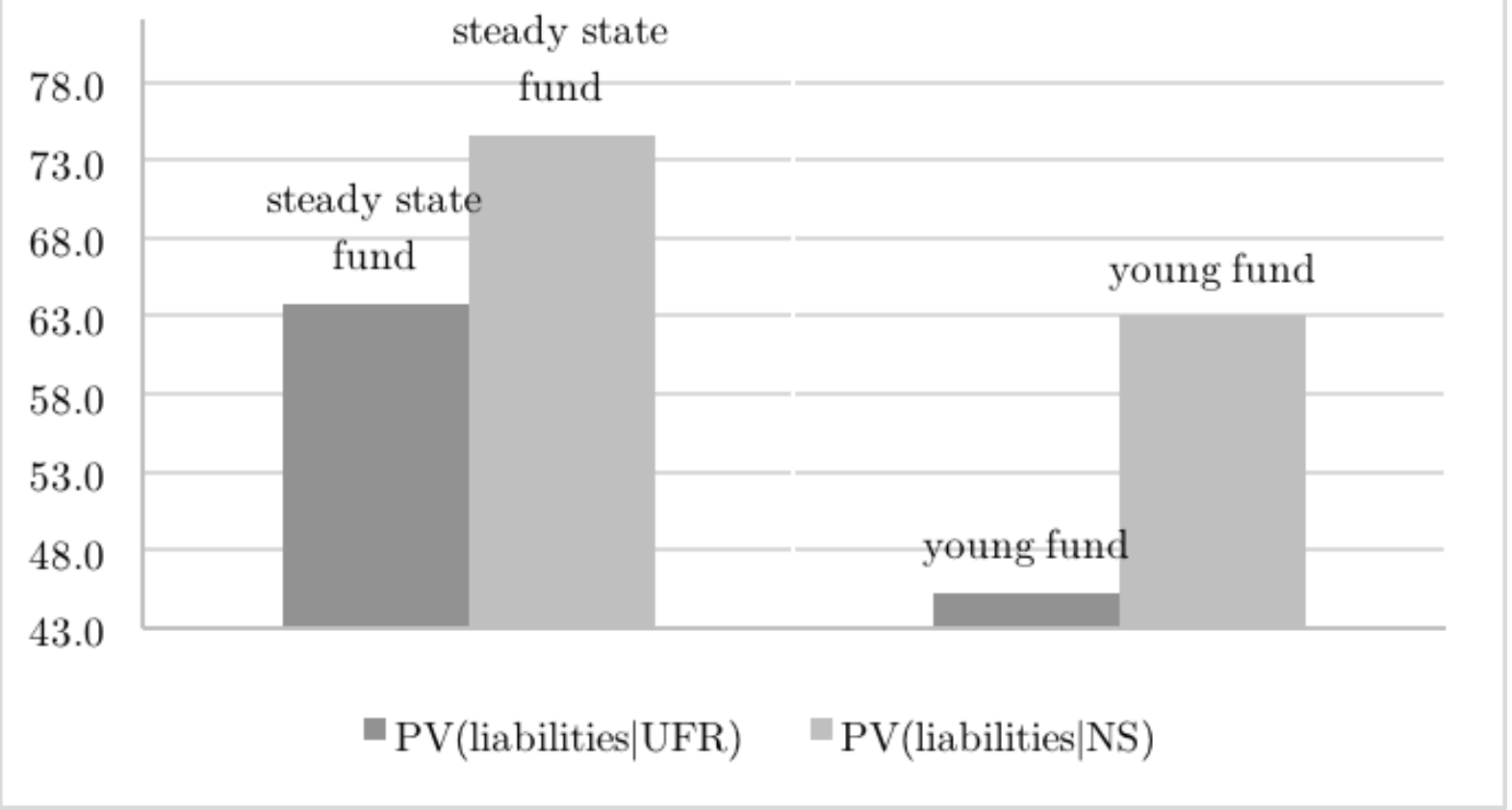

Figure 9 Welfare effects of liability valuation: a thought experiment

The figure depicts the liability payout schedules and present values of these liabilities for two hypothetical pension funds: a large and a small and young fund. The upper panel depicts the cash flow structures assumed for the two pension funds in the calculation of welfare effect when one switches from the current regulatory curve to the one we propose for liability valuation. The lower panel compares the present values of liabilities of the two hypothetical funds, where liabilities are either discounted by the shifted UFR or by the extrapolated Nelson Siegel curves. 


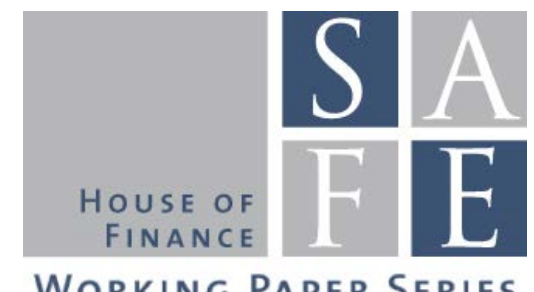

WORKING PAPER SERIES

\section{Recent Issues}

No. 237 Nathanael Vellekoop

No. 236 Aleksey Kolokolov, Giulia Livieri, Davide Pirino

No. 235 Christian Kubitza, Loriana Pelizzon, Mila Getmansky Sherman

No. 234 Alejandro Bernales, Nicolás Garrido, Satchit Sagade, Marcela Valenzuela, Christian Westheide

No. 233 Baptiste Massenot, Yuri Pettinicchi

No. 232 Jannic Alexander Cutura

No. 231 Benjamin Clapham, Peter Gomber, Jens Lausen, Sven Panz

No. 230 Yalin Gündüz, Giorgio Ottonello, Loriana Pelizzon, Michael

Schneider, Marti G.

Subrahmanyam

No. 229 Daniel Harenberg

No. 228 Roberto C. Panzica

No. 227 Mila Getmansky, Ravi Jagannathan, Loriana Pelizzon, Ernst Schaumburg, Darya Yuferova

No. 226 Loriana Pelizzon, Marti G.

Subrahmanyam, Davide Tomio, Jun Uno
Explaining Intra-Monthly Consumption Patterns: The Timing of Income or the Timing of Consumption Commitments?

Statistical Inferences for Price Staleness

The Pitfalls of Central Clearing in the Presence of Systematic Risk

A Tale of One Exchange and Two Order Books: Effects of Fragmentation in the Absence of Competition

Can Households See into the Future? Survey Evidence from the Netherlands

Debt Holder Monitoring and Implicit Guarantees: Did the BRRD Improve Market Discipline?

Liquidity Provider Incentives in Fragmented Securities Markets

Lighting up the Dark: Liquidity in the German Corporate Bond Market

Asset Pricing in OLG Economies With Borrowing Constraints and Idiosyncratic Income Risk

Idiosyncratic Volatility Puzzle: The Role of Assets' Interconnections

Stock Price Crashes: Role of Slow-Moving Capital

Central Bank-Driven Mispricing? 